\title{
1 Lateral resistance of 'rigid' pipelines and cables on rocky seabeds
}

3 Submitted to Canadian Geotechnical Journal on 5/4/2018

4

5 Terry Griffiths

6 Corresponding author

7 Oceans Graduate School

8 The University of Western Australia,

9 Crawley, WA 6009,

10 Australia

$11 \quad$ Phone +61404684712

12 Email: terry.griffiths@ research.uwa.edu.au 


\section{David J. White}

14 The University of Southampton,

15 Highfield, Southampton

16 United Kingdom

17 (also affiliated with the University of Western Australia)

\section{Scott Draper}

20 Oceans Graduate School

21 The University of Western Australia,

22 Crawley, WA 6009,

23 Australia

\section{Adam Leighton}

26 School of Civil, Environmental and Mining Engineering

27 The University of Western Australia,

28 Crawley, WA 6009,

29 Australia 
Liang Cheng

33 Oceans Graduate School

34 The University of Western Australia,

35 Crawley, WA 6009,

36 Australia

37

\section{Hongwei An}

39 Oceans Graduate School

40 The University of Western Australia,

41 Crawley, WA 6009,

42 Australia

43

44 Antonino Fogliani

45 Dept. of Civil, Environmental and Mining Engineering

46 The University of Western Australia,

47 Crawley, WA 6009,

$48 \quad$ Australia

49 Videos: 1

50 Figures: 22

$51 \quad$ Words: 5648

52 Keywords: Lateral resistance; On-bottom stability; Pipeline/cable; Rocky seabed;

53 Abrasion/failure. 


\section{ABSTRACT}

Accurate assessment of lateral resistance is critical to ensure the on-bottom stability and integrity of subsea pipelines and cables in the oil/gas and marine renewable energy industries. However, on rocky seabeds recommend practices provide limited recommendations on pipe/seabed interaction, suggesting only a single value for the friction coefficient of 0.6. This paper reports on a programme of physical experiments and theoretical modelling investigating the lateral resistance of pipes on rocky seabeds. It is shown that the peak and mean effective friction can significantly exceed the interface (or Coulomb) friction coefficient when the pipe diameter (D) is similar to the median rock diameter $\left(d_{n 50}\right)$. Only when the pipe diameter becomes large compared to the rock size does the mean effective friction approach the interface friction. The effective friction coefficient was found to vary with variability in rock size and shape, as well as the length of pipe relative to median rock diameter. Each of these findings is reproduced well using the theoretical model and demonstrating that the effective lateral friction coefficient maybe higher than 0.6 for mean friction, and significantly higher for peak friction. This implies that inaccuracy may exist in current design, which may be rectified using the theoretical model. 


\section{INTRODUCTION}

In many situations subsea pipelines and cables must be routed across rocky seabeds where soft or granular soils may have been washed away by persistently aggressive waves and currents, creating challenging conditions for stabilisation. In these situations the seabed characteristics can have a huge impact on the cost of submarine pipelines (Griffiths et al., 2010) and cable installations (Sharkey et al., 2013). For example, a high number of installed wave and tidal facilities have required cable stabilisation measures (Sharkey, 2013) such as armour casings and concrete mattresses (at the EMEC site, off the Scottish coast), rock dumping (at the Wavehub site off the Cornish coast) and horizontal directional drilling (the MCT SeaGen project in Strangford Lough, Northern Ireland).

Examples of cables installed over rocky seabeds can be found at the EMEC wave and tidal test sites in the Pentland Firth (The Crown Estate, 2015) as illustrated in Figure 1. Slightly different rocky seabed conditions are also prevalent around the proposed tidal energy sites in the Bay of Fundy that feature medium to coarse gravel and cobbles (Stark et al., 2013), including potentially mobile gravel dunes as shown in Figure 1. Rocky seabeds also occur on the Australian continental shelf along hydrocarbon pipeline and cable routes, including relatively flat limestone pavements and calcarenite caprock, as described by Sims et al. (2004) and Duncan and Gavrilov (2012).

The prevailing design methodology (The Crown Estate, 2015) used to evaluate the on-bottom stability of pipelines and cables on rocky seabed for the marine renewable energy industry is DNVGL-RP-F109 (DNV GL, 2017), which was originally written for the offshore oil and gas industry for hydrocarbon-containing pipelines. This recommended practice features three different approaches to stability design, which compare the actions on the pipe/cable, including pipe weight, hydrodynamic loading and geotechnical seabed restraint. With respect to the last of these actions - i.e. the seabed resistance between pipelines and rocky seabeds - Section 3.4.6 
of the recommended practice states "The coefficient of friction $\mu$ can normally, for a concrete coated pipe, be taken as ... 0.6 on rock" where "Rock is here defined as crushed rocks with a 50 per cent diameter fractile larger than $50 \mathrm{~mm}$ " (DNV GL, 2017). While the literal interpretation of this statement suggests it is not intended to apply to the particular condition of cables on naturally occurring rocky seabeds as shown in Figure 1, this recommended approach is used widely for pipe stability design on rocky beds. This is despite the fact that the blanket adoption of $\mu=0.6$ cannot capture different rock types or pipe coating type - noting that cables and small diameter pipelines are rarely coated with concrete, but instead have various forms of outer layer made from other materials. The use of a single value is also at odds with conventional practice for pipelines on sand and clay, where it is widely recognised that both sediment type and pipe coating affect the friction behaviour (e.g. White et al. (2012), Hill et al. (2012), SAFEBUCK (2015), and design practice usually involves direct measurement of the relevant parameters.

From the perspective of pipeline and cable design, the use of a blanket value for the effective lateral friction coefficient can lead to inaccurate stability assessment. This leads to concerns involving the reliability and integrity of cables and pipelines, which often represent single points of failure within the overall system for both oil and gas and renewables. Furthermore it has been noted (Jee, 2016), (Boehme and Robson, 2012) that up to $80 \%$ of insurance claims from wind farm operators have been cable related, hence their integrity remains critical to the financial performance of the projects. In addition to improvements in reliability, there are also potential opportunities to reduce design and maintenance costs through improved design of cables and pipes on rocky seabed. For instance, the oil and gas industry is experiencing a phase of lower commodity prices driving significant industry innovation, whilst the offshore wind industry is experiencing a fall in subsidies while also attempting to 'close the gap' to the installed cost of non-renewable energy. 
121 Motivated by these integrity and cost drivers, the objectives of this research are to improve

122 understanding of the interaction between subsea pipelines and cables on rocky seabeds,

123 particularly focusing on the resulting geotechnical lateral resistance to movement. The

124 overarching aim is to develop an improved modelling approach to capture pipeline and cable

125 interaction with rocky seabed, which is able to account for different rock types and

126 pipeline/cable coating.

127 As discussed by Robertson et al. (2015), 'pipelines' and 'cables' cover a wide range of external 128 hydrodynamic diameters (D), ranging from around $50 \mathrm{~mm}$ to over $1.2 \mathrm{~m}$, and have a wide range 129 of purposes, including: rigid steel pipelines comprised of monolithic steel; flexible pipes 130 comprising un-bonded concentric layers of steel and polymeric materials; umbilicals 131 comprising multiple cores of pipes, electric and fibre-optic wires and fillers encased in

132 helically-wound armour wires and a polymeric sheath; and cables, primarily used for power 133 and data transmission, typically comprising concentric layers of copper / fibre-optic cores,

134 fillers, helically wound armour layer and a polymeric sheath. For simplicity, this paper refers 135 to each of these applications as 'pipes' from hereon.

136 The remainder of this paper is set out as follows. In Section 2 an improved model for pipe-rock

137 interaction is introduced, and the key characteristics which influence the interaction are 138 explored theoretically. Section 3 then presents results from a series of laboratory experiments 139 in which pipes of various diameter have been dragged across different rocky seabeds. Section 1404 then back analyses the experiments using the improved model, so as to demonstrate the ability 141 of the model to accurately capture the effective lateral friction coefficient. Discussion and 142 conclusions are then given in Section 5. 


\section{THEORETICAL MODELLING}

145

146 introduced (Wilkinson et al., 1988):

$$
\mu_{e f f}=\frac{H}{V}=\frac{\mu_{0}+\tan (\theta)}{1-\mu_{0} \tan (\theta)}
$$
where $H$ is the limiting horizontal resistance prior to pipe movement, $V$ is the vertical reaction

156 force at the point of contact (equal to the submerged weight per unit length of the pipe, if the seabed is flat in the direction parallel to the pipe and hydrodynamic loading is ignored), and $\theta$ is the angle at which the pipeline is moving relative to the horizontal. An important feature of

159 Equation (1) is that it effectively separates the effect of the macro-scale seabed slope from the

160 micro-scale surface interaction (defined by $\mu_{0}$ ). Hence Equation (1) implicitly assumes that the 161 roughness length scales associated with a rocky bed can be separated into macro and micro 162 scales.

163 Since Equation (1) relates the lateral resistance to the vertical contact, it effectively replaces the 164 interface friction as the appropriate friction coefficient to use in an on-bottom stability analysis 165 on an irregular rocky seabed. With this in mind, three aspects of Equation (1) are useful to 
166

167

168

169

170

171

172

173

174

175

176

177

178

recognise. Firstly, the equation implies that the effective friction is not symmetric between uphill and downhill sliding, as shown in Figure 2 for $\mu_{0}$ values of 0.3 and 0.6. Hence the mean sliding resistance of a pipe that traverses over a 'flat' seabed with macro-scale asperity is greater than the friction coefficient for a flat seabed, and this has obvious implications for assessing the dynamic stability of a pipe. Secondly, the effective lateral friction coefficient becomes infinite as $\mu_{0} \tan \theta \rightarrow 1$ (e.g. with a $\mu_{0}$ of 0.6 , a wall steeper than $59^{0}$ causes infinite lateral resistance). Finally, the effective lateral friction coefficient becomes negative when $-\tan \theta>\mu_{0}$, at which point the pipe would freely slide down a slope.

\subsubsection{A theoretical model for pipe on rocky seabed}

With respect to developing a theoretical model to estimate the effective friction coefficient experienced by a rigid pipeline as it is dragged along on an arbitrary rocky seabed, Equation (1) can be used as the basic starting point. The only additional ingredient that is needed is to model how the pipeline conforms to the seabed so that (i) the location of the contact points can be determined and (ii) both the vertical reaction and the local angle at which the pipeline moves can also be determined at the contact points. These values can then be fed into Equation (1) to determine the effective friction coefficient for the pipe at a given location.

For convenience, in this paper it is assumed in the majority of the analysis that the pipeline is rigid and horizontal so that it has effectively only one contact point. This assumption greatly simplifies the calculation of the contact points (which is simply the highest point of contact on the seabed beneath the pipeline) and the vertical force, and needs only be adapted slightly to allow for comparison with the experiments outlined in Section 3. Nevertheless, extensions to account for pipeline flexural rigidity are reasonably straight-forward and are the subject of ongoing work by the authors. 


\subsection{Modelling pipelines on rocky seabeds}

190 The theoretical model outlined in the preceding section may be used to assess the effective

191 friction coefficient for a pipeline on any rocky seabed. In general, however, it is useful to

192 introduce some parameters to define the pipeline and seabed, and to develop some intuition for

193 how these parameters influence the mean and peak effective friction coefficient. With this in

194 mind, it is assumed that the seabed is comprised of a range of rock particles having a well-

195 defined median rock size $d_{n 50}$ (where the subscript $\mathrm{n}$ indicates that this refers to the rock

196 particle size rather than the corresponding sieve mesh opening size), a coefficient of uniformity

$197 C_{U}$ and some known particle shape or angularity and a relative packing density. Dimensional

198 reasoning and noting invariance to a transformation of dimensions then implies that:

$$
\frac{\mu_{e f f}}{\mu_{0}}=f\left(\mu_{0}, \frac{D}{d_{n 50}}, \frac{L}{d_{n 50}}, C_{U}, \text { Shape, Packing density }\right)
$$

199 Where $D$ is the pipeline diameter, $L$ is the length of rigid pipeline that is modelled (and thus

200 defines the length over which the contact point must occur). In the following subsections each

201 of the parameters $D / d_{n 50}, L / d_{n 50}$ and $C_{U}$ are explored theoretically for rocky beds comprised of both circular and square particles.

\subsection{Effect of relative pipe diameter $(D / d)$}

204 To investigate the effect of the relative pipeline diameter on the effective friction coefficient, 205 the friction coefficient for a pipe sliding over a $2 D$ surface profile comprising circular and 206 square (oriented at $45^{\circ}$ ) prisms is shown as illustrated in Figure 3(a) and (b). At each location 207 along the seabed, the pipes have been lowered down until contact with the seabed just occurs. 208 Using a central difference scheme, the gradient of the pipe paths can then be found and, in turn, 209 the peak friction coefficient for each $D / d$ diameter ratio. The mean friction for each $D / d$ 210 diameter ratio is also found by a linear average of the effective friction over a distance of $d$. For 
211 the particular case of $\mu_{0}=0.3$, the mean and peak effective friction coefficients representative

212 of all locations of the pipe on the seabed can be calculated using Equation (1) and are given in 213 Figure 3(c) and (d) for ratios of pipe diameter, $D$, to seabed 'particle' diameter, $\mathrm{d}$ from $D / d=$ 2140.1 to 100 . This figure indicates some important points. Firstly, for sufficiently large $D / d$ (> $215 \sim 40$ in Figure 3(c) and (d)), the influence of seabed particle size is substantially diminished and 216 the sliding profiles of the pipes become 'smooth', with peak effective friction coefficient being 217 less than $10 \%$ greater than the interface friction and mean friction coefficient being less than $2180.03 \%$ greater. In contrast, for small $D / d(<40)$ the influence of seabed particle size becomes 219 increasingly important in determining both the mean and peak effective friction coefficients; in 220 the particular examples considered for the square particles there is a cut-off of peak friction 221 which corresponds to the pipe moving upwards at the slope angle of the seabed $\left(\theta=45^{\circ}\right)$, 222 whereas for the circular particles an infinitesimally small pipe will face a sufficiently steep wall, 223 giving infinite peak friction. This example therefore highlights the importance of pipe diameter, 224 relative to particle size, on the effective friction coefficient. Only when $D / d$ is larger than some 225 value will the interface friction provide a good estimate of the effective friction coefficient.

226 Secondly, it can be noted in Figure 3(c) and (d) that the peak friction for circular particles is 227 higher than for square, reflecting the steep edge of these particles. However, the mean friction 228 is lower. This shows that while changes in peak and mean friction occur over similar ranges of $229 D / d$, particle shape affects the relative ratio of peak to mean friction.

\subsection{Effect of relative pipe length $(L / d)$}

231 The contact point for a rigid pipeline can occur at any point along its length. The effect of this 232 on the lateral friction can be understood by introducing the concept of skyline profiles. By way 233 of analogy, the city skylines for Perth in Western Australia and New York in the United States 234 are presented in Figure 4. The height of the buildings comprising each city are similar, but the 
difference between the outline profiles is driven by the number of rows of buildings comprising the city - Perth being much smaller than New York. If a pipe of suitable diameter were dragged over each city skyline from left to right of Figure 4, the Perth skyline is much rougher while the New York skyline is comparatively 'smooth' due to the depth of buildings contributing to the outline profile.

The relevance of these observations to the lateral resistance of a rigid pipe sliding across a rocky seabed arises because the length of the pipe is a proxy for the number of skyline rows required to represent the trajectory of the pipe when pulled laterally. In essence a longer pipe would be needed to pass over the New York skyline.

To explore the effect of effective pipe length quantitatively, Figure 5 considers a pipe being dragged over a seabed comprising several rows of uniform spherical particles of diameter $d$, with each row having a random relative position (or phase). The random alignment of rows of particles alters the skyline profile. Increasing the number of rows comprising the skyline (i.e. increasing the pipe length) progressively smoothens the profile.

The effect of both $D / d$ and $L / d$ on the peak lateral resistance are shown in Figure 5 for both square and circular particles. To calculate these results the pipe has been assumed to remain horizontal (i.e. the opposite ends cannot rise and fall with the 3D topography) so the analysis effectively follows a 2D skyline, calculating the friction at any instant based on Equation (1), with the instantaneous direction of pipe motion giving the angle $\theta$. An ensemble of 20 simulations have been undertaken in each case given that the alignment of the rows is random. The results indicate that as the length of the pipe increases the skyline contains an increasing number of rows, and so the peak friction returns to the interface sliding coefficient, $\mu_{0}$, across all $D / d$ values. This trend is observed for both the circular and square particles, although the reduction with pipe length is slower for the square particles owing to their increased angularity. 


\subsection{Rock with non-uniform particle size distribution}

260 The analysis in Section 2.4 can be extended easily to consider non-uniform particles that form 261 irregular synthetic 3D seabeds defined by a grading with median particle diameter $d_{n 50}$ and 262 grading width $C_{U}=d_{85} / d_{15}$. Figure 6 provides examples for both circular and square particles, with the orientation of the square particles fixed (in this work a Rosin-Rammler distribution has 264 been assumed to define the particle size distribution based on $d_{n 50}$ and $C_{U}$; see (Rosin and Rammler, 1933). Assuming again that the pipe is rigid and horizontal, a 3D skyline profile is formed by aligning a number of $2 \mathrm{D}$ profiles, with the average lateral spacing of the profiles taken as $d_{n 50}$. As shown in Figure 7 the size of the largest particle increases as the pipe length (and thus the number of rows of particles in the skyline) gets larger. The influence of $D / d_{n 50}$, number of rows in the skyline (i.e. $L / d_{n 50}$ ) and the value of $C_{U}$ has been explored numerically for a $1 \mathrm{~m}$ long domain and $d_{n 50}$ of $100 \mathrm{~mm}$. At least 16 independent simulations have been performed for each case, using an arbitrary interface friction $\mu_{0}$ of 0.3 . The ratios of absolute maximum and mean friction coefficient to interface friction coefficient have been plotted in

273 Figure 8 . The results show that

- For the special case of $C_{U}=1$, the results degenerate to the case of uniform particle sizes;

- For all of the values of $C_{U}$ and any number of rows in the skyline, the mean and maximum friction coefficients tend towards the interface friction as $D / d_{n 50}$ increases;

- As $C_{U}$ increases, for a given $D / d_{n 50}$ and a given number of rows in the skyline, the mean and maximum friction coefficients tend to increase;

- As the number of rows in the skyline increases, the mean and maximum friction coefficients tend to decrease 
Overall, the parameters $D / d_{n 50}, C_{U}$ and number of rows in the skyline all influence the effective friction coefficient, with their combined effect on the trajectory of the pipe controlling the mean and peak effective friction coefficient.

\section{PHYSICAL MODELLING OF LATERAL RESISTANCE}

To confirm the general findings in Section 2 physical modelling of the lateral resistance between pipe and rock has been undertaken using a purpose-built test rig. The operation of the test rig is demonstrated in Video 1.

\subsection{Experimental test set-up}

\subsubsection{Lateral resistance test rig}

The lateral resistance test rig is shown in Figure 9. The key features of the test rig are:

- Two electrically-driven constant-velocity linear actuators to push or pull a model pipe laterally over a $1 \mathrm{~m}$ wide by $1 \mathrm{~m}$ long test bed;

- The actuators pivot in the vertical plane so the model test pipe may rise and fall vertically as it traverses the model seabed, also allowing the model pipe to yaw (as defined in Figure 10) so that in general two points of contact with the seabed are maintained. This aspect differs slightly to the theoretical modelling described in Section 2 above, where the pipe remained horizontal;

- The lateral force applied to the model pipe is monitored via a calibrated load cell.

The control of the linear actuators was via a single toggle-switch driving forwards and reverse movement. The load cell and displacement transducers were monitored digitally using the datalogging system described by Gaudin et al. (2009). The calibration of the load cell accounted for the mechanical leverage of the system (Figure 9). 


\subsubsection{Model pipes tested}

307 The test rig was used to push and pull model pipes of $1 \mathrm{~m}$ length laterally a distance of $1 \mathrm{~m}$

308 across the model seabeds. The model pipes were all of hollow steel construction, with the

309 bottom contact points of the pipes rapidly forming 'bright' steel finishes as the rocks abraded 310 any other surface finish. The properties of the model pipes tested are given in Table 1, and

311 shown in Figure 11. The contact weight of the pipe on the model seabed varies slightly

312 depending on the position of the linear actuators and therefore how much actuator weight is

313 being born by the pipe. Thus the 'near' and 'far' measured weights give the weight gradient

314 which has been used for calculating the pipe weight at any position along its travel.

315 Table 1 Model pipe properties

\begin{tabular}{|c|c|c|c|c|c|}
\hline \multirow[t]{2}{*}{ Pipe } & \multirow{2}{*}{$\begin{array}{c}\text { Diameter } \\
{[\mathrm{mm}]}\end{array}$} & \multirow{2}{*}{$\begin{array}{c}\text { Bottom } \\
\text { Surface } \\
\text { Roughness } \\
\text { Ra }[\mathrm{mm}]\end{array}$} & \multicolumn{2}{|c|}{ Weight [N/m] } & \multirow{2}{*}{$\begin{array}{c}\text { Weight Gradient } \\
{[\mathrm{N} / \mathrm{mm}]}\end{array}$} \\
\hline & & & Near & Far & \\
\hline 1 & 42.5 & 4.54 & 121.4 & 101.6 & \multirow{4}{*}{-0.02058} \\
\hline 2 & 61.0 & 2.94 & 144.2 & 121.4 & \\
\hline 3 & 101.5 & 4.03 & 188.7 & 169.2 & \\
\hline 4 & 169.0 & 5.93 & 248.8 & 228.6 & \\
\hline
\end{tabular}

\subsubsection{Model rocky seabeds tested}

317 A series of four model rocky seabeds were constructed for this research. Each test seabed was

318 formed by placing a single layer of brown and white granite cobbles and gravels onto a thick

319 layer of tile adhesive covering a $1 \mathrm{~m}$ by $1 \mathrm{~m}$ board of $18 \mathrm{~mm}$ thick plywood (Figure 12). They

320 are generally representative of different types of irregular rocky seabed relief.

321 Using a representative sub-sample of $>30$ particles of each rock type, the following

322 measurements were made on each particle: (i) longest and shortest lengths, and a third 323 approximately orthogonal length; (ii) the mass; and (iii) the displacement (immersed in water). 
324 The particles were also photographed from an inclination of $45^{0}$ while resting on a level

325 backdrop. The Rosin-Rammler equation was subsequently fitted by a least-squares method to

326 obtain the median particle mass $M_{50}$ and $C_{U}$ values for each rock grading. The mean and

327 standard deviation of each of these parameters is given in Table 2 and a plot of the measured

328 grading curves is presented in Figure 13.

329 Table 2 Model rock properties

\begin{tabular}{|c|c|c|c|c|c|c|c|c|c|c|}
\hline $\begin{array}{c}\text { Rock } \\
\text { Sample }\end{array}$ & & $\begin{array}{c}\text { L1 } \\
{[\mathbf{m m}]}\end{array}$ & $\begin{array}{c}\mathbf{L 2} \\
{[\mathrm{mm}]}\end{array}$ & $\begin{array}{c}\mathbf{L 3} \\
{[\mathrm{mm}]}\end{array}$ & $\begin{array}{c}\text { Mass } \\
{[\mathrm{g}]}\end{array}$ & $\begin{array}{l}\text { Density } \\
{\left[\mathrm{g} / \mathrm{cm}^{3}\right]}\end{array}$ & $\begin{array}{c}\text { M50 } \\
{[\mathbf{m m}]}\end{array}$ & $\begin{array}{c}\text { dso } \\
{[\mathbf{m m}]}\end{array}$ & $\begin{array}{c}\text { dn50 } \\
{[\mathrm{mm}]}\end{array}$ & $\mathbf{C u}_{\mathbf{U}}[-]$ \\
\hline $\begin{array}{r}\text { Blue } \\
\text { Gravel } \\
(\mathrm{BG})\end{array}$ & $\begin{array}{r}\text { Mean } \\
\pm \text { SD }\end{array}$ & $\begin{array}{r}13.6 \\
\pm 7.7\end{array}$ & $\begin{array}{r}5.8 \\
\pm 2.9\end{array}$ & $\begin{array}{r}8.9 \\
\pm 4.1\end{array}$ & $\begin{array}{r}1.4 \\
\pm 1.9\end{array}$ & $\begin{array}{r}2.65 \\
\pm 0.02\end{array}$ & 0.45 & 6.6 & 5.5 & 2.19 \\
\hline $\begin{array}{l}\text { White } \\
\text { Round } \\
\text { (WR) }\end{array}$ & $\begin{array}{r}\text { Mean } \\
\pm \text { SD }\end{array}$ & $\begin{array}{r}65.3 \\
\pm 9.4\end{array}$ & $\begin{array}{r}34.3 \\
\pm 7.6\end{array}$ & $\begin{array}{l}50.2 \\
\pm 8.6\end{array}$ & $\begin{array}{l}171 \\
\pm 67\end{array}$ & $\begin{array}{r}2.64 \\
\pm 0.12\end{array}$ & 164.0 & 47.2 & 39.6 & 1.30 \\
\hline $\begin{array}{l}\text { White } \\
\text { Angular } \\
\text { (WA) }\end{array}$ & $\begin{array}{r}\text { Mean } \\
\pm \text { SD }\end{array}$ & $\begin{array}{r}74.0 \\
\pm 15.4\end{array}$ & $\begin{array}{l}19.7 \\
\pm 2.0\end{array}$ & $\begin{array}{r}42.9 \\
\pm 11.2\end{array}$ & $\begin{array}{r}125 \\
\pm 56\end{array}$ & $\begin{array}{r}2.69 \\
\pm 0.07\end{array}$ & 121.0 & 42.3 & 35.6 & 1.38 \\
\hline $\begin{array}{l}\text { Brown } \\
\text { Angular } \\
\text { (BA) }\end{array}$ & $\begin{array}{r}\text { Mean } \\
\pm \mathrm{SD}\end{array}$ & $\begin{array}{l}117.2 \\
\pm 31.9\end{array}$ & $\begin{array}{r}55.2 \\
\pm 16.1\end{array}$ & $\begin{array}{r}82.9 \\
\pm 20.0\end{array}$ & $\begin{array}{r}694 \\
\pm 475\end{array}$ & $\begin{array}{r}2.51 \\
\pm 0.11\end{array}$ & 521.6 & 70.5 & 59.2 & 1.36 \\
\hline
\end{tabular}

\subsection{Lateral resistance test matrix}

332 As described above, the models comprised 4 pipe diameters and 4 types of rock sample, giving

33316 pipe/rock combinations. Each pipe/rock combination was tested for 2 "push" and 2 "pull"

334 traverses of the board. After each of these 4 traverses, the rock test board was rotated by $90^{0}$

335 and the traverses were repeated, giving a total of 16 traverses for each of the 16 combinations

336 of rock and pipe.

\subsection{Experimental results}

338 For each test the digital data record was post-processed to convert the signal to a force/time 
history using the load-cell calibration and accounting for the mechanical advantage of the system. The lateral forces were then converted to effective friction by dividing by the pipe effective weight depending on pipe lateral position. An example of the test results is presented in Figure 15 for the Brown Angular rock and the $42.5 \mathrm{~mm}$ diameter pipe. These results show many discrete isolated peaks in the lateral resistance, which vary significantly in both amplitude 344 and position for each of the 16 different test sweeps. These features were observed across all of 345 the tests, however the amplitude and frequency of peaks varied between rock types and model 346 pipe diameters.

347 On a small number of occasions (less than once per test), the force applied to a rock was 348 sufficient to break the bond with the wooden base or to fracture a rock particle as shown in 349 Figure 16, so the peak in resistance was capped by the strength of the test bed or the rock itself 350 rather than the true limit of the lateral pipe-seabed friction associated with the intact topography 351 of the model seabed. These events were rare, so have a negligible effect on the mean effective 352 friction coefficients, but highlight the high forces applied at the pipe-seabed contact points as 353 expected from the implications of Figure 2 for large slope angles.

354 The horizontal resistance data was obtained at fixed displacement intervals. By sorting these 355 effective friction data records into descending order, the distribution of instantaneous effective 356 friction is obtained (Figure 15). These results show that very large friction coefficients ( $\mu_{e f f} \geq$ 357 1) and negative friction coefficients (when the pipe was descending such that the load cells read 358 tension during a push stage and vice versa) occur only for relatively small fractions of the total 359 displacement $(\$ 5 \%)$, as would be expected based on Figure 2.

360 Key aspects of the test results are summarised in Figure 17. The peak friction values always 361 significantly exceed the median friction, which is indicative of the interface friction coefficient $362 \mu_{0}$. The peak frictions generally increase as $\mathrm{D} / \mathrm{d}_{\mathrm{n} 50}$ reduces, as do the mean frictions. The rock 363 shape is also observed to influence the results, especially for smaller pipes and for the peak 
friction measured.

365 Each of these figures and the above general trends are consistent with the previously described 366 theoretical predictions, show that the theoretical framework captures the mechanisms and 367 behaviours that underpin lateral resistance behaviour of pipes on rocky seabeds.

\section{BACK-ANALYSIS OF EXPERIMENTAL RESULTS}

\subsection{Comparison with numerical prediction from scanned surface profiles}

The results in Section 3 qualitatively corroborate the trends identified in Section 2. However, in any practical situation it is useful to have a means to quantitatively predict the lateral friction coefficient experienced by a pipe on a rocky seabed. To test the ability of the theoretical model to make quantitative predictions, back-analysis of the brown angular rock sample experiments were undertaken. To properly capture the shape and particle size distribution of this rock the experimental seabed was scanned using a 3D scanner (see Figure 18); this scanner measured the seabed with an accuracy of $\pm 1 \mathrm{~mm}$, with a resolution of one measurement per square millimetre.

Using the scanned seabed profile it is possible to make predictions using the theoretical model in Section 2.1, provided three additional aspects are considered. Firstly, a value for the interface friction $\mu_{0}$ must be defined. To estimate this value the median effective friction coefficient value measured in the experiments is assumed to equal $\mu_{0}$. The rationale behind this assumption is that the pipe is expected to move upwards as much as it moves downwards as it is dragged across the rocky bed; thus the median resistance should correspond to horizontal motion, at which point $\mu_{e f f} \sim \mu_{0}$. To sense-check this assumption, comparison to published rock / steel interface frictions by Ziogos et al. (2015) has also been undertaken. The published values range from 0.5 to 0.7 for steel roughness values $\mathrm{Ra}$ greater than $5 \mu \mathrm{m}$, and from 0.1 to 0.3 for $\mathrm{Ra}$ values less than this. The measured test pipe bottom surface roughnesses presented in Table 1 
and median friction coefficient presented in Figure 16 fall within the range of the Ziogos et al.

389 (2015) results.

Secondly, so as to numerically account for the limiting resistance associated with rock particle

391 breakage, a peak effective friction coefficient of 25 is assumed where numerically resistance is

392 predicted to be infinite.

393 Thirdly, in the theoretical model described in Section 2 it was assumed that the pipe was rigid

394 and horizontal, so that it had one contact point along its length. However as observed in Video

395 1, the physical test pipes were free to yaw as they translated laterally. This results in two contact 396 points and can increase the lateral resistance compared to a horizontal pipe with only one 397 contact point (Griffiths et al., 2017). To compare the numerical predictions of lateral resistance 398 against the measured physical lateral resistances, the vertical position and yaw angle of the pipe 399 on 2 points of rigid contact were determined using geometric arguments as the pipe was slid 400 laterally across the model seabed. It was then possible to define the proportion of pipe weight 401 being taken by each of the 2 contact points as follows:

$$
\frac{R_{1}}{W s}=\frac{L / 2-x_{2}}{x_{1}-x_{2}}
$$

402 and

$$
\frac{R_{2}}{W S}=1-\frac{R_{1}}{W S}
$$

where $R_{1}$ and $R_{2}$ are the reaction forces, $x_{1}$ and $x_{2}$ indicate the contact locations along the 404 pipeline, $W S$ is the total weight of the pipe and $L$ is the length of the pipe $(1 \mathrm{~m}$ in the tests in 405 this paper). Combing Equation (3) and (4) with Equation (1) then leads to $n$ general expression 406 for the total horizontal force

$$
H=R_{1}\left(\frac{\mu_{0}+\tan \theta_{1}}{1-\mu_{0} \tan \theta_{1}}\right)+R_{2}\left(\frac{\mu_{0}+\tan \theta_{2}}{1-\mu_{0} \tan \theta_{2}}\right),
$$


408 Where $\theta_{1}$ and $\theta_{2}$ describe the trajectories (relative to horizontal) of each point of contact on the

409 pipe. The effective friction coefficient then follows from $\mu_{e f f}=H / W_{s}$.

\subsubsection{Numerical simulation results}

411 Each pipe was laid down onto the scanned numerical seabed and translated laterally across the 412 full width in each cardinal direction. Two cases of pipe boundary condition were considered 413 rigid horizontal pipe which is constrained to move in $2 \mathrm{D}$ (as per the approach taken in Section 414 2) and a 'yawing' pipe which can move in $3 \mathrm{D}$ and compares to the boundary conditions relevant 415 to the physical tests as shown in Figure 10. The pipe/rock contact points together with the 416 variation in pipe end elevation are presented in Figure 18. The distribution of effective friction 417 coefficient measurements for the example cases of brown angular rock and $61 \mathrm{~mm}$ pipe are 418 compared to the 3D numerically predicted results in Figure 19. The numerical results use a 419 value of $\mu_{0}$ equal to the average median friction and adopt an effective friction factor of 25 to 420 represent 'infinite' friction events. The comparison shows good agreement across the range of 421 test directions and across the distributions of effective lateral resistance. The results therefore 422 confirm that the lateral resistance of a pipe can be predicted from a suitable digital 423 representation of the seabed surface profile.

\subsection{Comparison of physical test results with numerical results for horizontal pipe on an} irregular finite 3D surface profile

427 In order to further compare the physical experimental results with the theoretical model, a series 428 of 16 irregular $1 \mathrm{~m}$ long quasi-3D skyline profiles were generated using both square and circular 429 particles as illustrated in Figure 6 for each of the physical rock sample types, matching the $\mathrm{d}_{\mathrm{n} 50}$ 430 and $\mathrm{C}_{\mathrm{U}}$ values. Consequently the seabed profile does not have the same level of detail as that in 431 Section 4.1, but all parameters are matched except the angularity/particle shape. The yawing 
432

nature of the physical pipeline is also not captured.

The results of the physical experiments (taken from Figure 16) are compared to the numerical results in Figure 20. With reference to these results, it can be seen that very similar trends are observed in the simulations and experiments, except that the former generally predict much lower effective friction coefficients. This observation confirms the importance of properly capturing particle shape and the contact condition between the pipe and seabed. Ignoring angularity and yawing leads to under-prediction of lateral resistance.

One advantage of the numerical calculations is that they enable the efficient investigation of various features of rock/pipe interaction which are difficult to undertake with the physical test results. One example is the correlation between particle size and the occurrence of lateral resistance peaks. Scatter-plots are presented in Figure 21 for the top 20 lateral resistance peaks versus the diameter of the largest rock located within $\mathrm{d}_{\mathrm{n} 50} / 2$ downstream of the resistance peak. These plots are presented for the 2 smallest pipes on the Blue Gravel and Brown Angular rock types. Although there is scatter in the results, Figure 21 shows that the peak resistances are associated with rocks that are much larger than $d_{n 50}$. However the peaks in effective friction coefficient relate to the difference in height of adjacent pipe positions (and particle sizes), rather than their absolute values. This point is demonstrated by looking at the particular case from Figure 21 of Brown Angular rock and $42.5 \mathrm{~mm}$ diameter pipe as shown in Figure 22, where it can be observed that the peak coefficient is caused not by the largest particle, but by the largest difference in size between adjacent particles.

\section{CONCLUDING DISCUSSION}

In this paper a theoretical model has been introduced to determine the effective lateral friction coefficient for a rigid pipe dragged across a rocky seabed. This model was used to develop 
some intuition of the effect of various parameters associated with the rock and pipe on lateral resistance. Physical experiments were then undertaken, which were found to both qualitatively and quantitatively agree well with the theoretical model.

Based on the work presented in this paper the following main conclusions have been formed:

- For a pipe on a realistic rocky seabed the effective friction coefficient can significantly exceed that due to microscopic asperities (encapsulated by the interface friction coefficient $\mu_{0}$ ) and can vary significantly from the value of 0.6 currently quoted in industry recommended practices. In particular, large variations in both the mean and peak effective friction coefficients are observed.

- The key parameters that influence the mean and peak effective friction coefficients include the interface friction coefficient $\mu_{0}$, the relative pipe diameter $\left(D / d_{n 50}\right)$, pipe length $\left(L / d_{n 50}\right)$ and the particle size distribution and shape of the rocks. In all cases, however, provided $D / d_{n 50}$ is sufficiently large (for a given pipe length and both particle size distribution and shape of rock) the mean effective friction coefficient will limit to the interface friction coefficient. The peak friction coefficient test results also appear to asymptote to $\mu_{0}$, but more slowly.

- A theoretical model can be used to accurately predict the mean effective friction coefficient for a pipe on a rocky seabed, provided that the interface friction coefficient is known and the seabed profile is known to sufficiently high resolution. Developing improved methods and practices for testing interface friction coefficients for pipe coatings on rock and characterising seabed rugosity will ensure these requirements are achievable in practice.

While the results of this work contribute useful insight and understanding to the behaviour of pipes on rocky seabeds, they do not yet represent a complete description of pipe interaction 
480

481

with rocky seabeds sufficient for general use in design. Further work which is presently underway extends on the work presented herein to account for hydrodynamic loading (altering the direction of loading), flexible pipelines and macro-scale variations in the seabed profile (not described by the characteristics of the rock).

\section{ACKNOWLEDGEMENTS}

This research forms part of the activities of the Centre of Offshore Foundation Systems (COFS), supported as a node of the Australian Research Council's Centre of Excellence for Geotechnical Science and Engineering (CGSE), and through the Fugro Chair in Geotechnics, the Lloyd's Register Foundation Chair and Centre of Excellence in Offshore Foundations and the Shell EMI Chair in Offshore Engineering. The first author acknowledges the support of the Australian Government for an Australian Postgraduate Award, the University of Western Australia for his Research Studentship and a University Club of Western Australia Research Travel Scholarship. The second author acknowledges the support of Shell, via the Shell EMI Chair. The third author acknowledges the support of the Lloyd's Register Foundation (LRF). LRF helps to protect life and property by supporting engineering-related education, public engagement and the application of research.

Thanks to Alex Duff for all his tremendous help leading the fabrication of the LRTR, as well as his enthusiastic advice and practical assistance during testing. The contribution of Shixin Yang through the related research undertaken in his final year project is also acknowledged with thanks. 


\section{REFERENCES}

DNV GL, 2017. On-bottom stability design of submarine pipelines.

Duncan, A.J. and Gavrilov, A., 2012. Low frequency acoustic propagation over calcarenite seabeds with thin, hard caps. Proceedings of Acoustics 2012 Fremantle.

Gaudin, C. et al., 2009. A wireless high-speed data acquisition system for geotechnical centrifuge model testing. Measurement Science and Technology, 20(9): 095709.

Griffiths, T., White, D., Draper, S., Leighton, A. and Fogliani, A., 2017. Lateral resistance of pipes on rocky seabeds - comparison of measured values with predictions from highresolution seabed scans and synthetic models. ASME 2017 36th International Conference on Ocean, Offshore and Arctic Engineering, Trondheim, Norway, p.^pp.

Griffiths, T.J., White, D.J. and Cheng, L., 2010. Progress in investigating pipe-soil-fluid interaction: The stablepipe jip. The Twentieth International Offshore and Polar Engineering Conference, p. $^{\wedge} \mathrm{pp}$.

Hill, A. et al., 2012. A new framework for axial pipe-soil resistance, illustrated by a range of marine clay datasets. Offshore Site Investigation and Geotechnics: Integrated Technologies-Present and Future, p. ${ }^{\wedge}$ pp.

Robertson, M. et al., 2015. The influence of pipeline bending stiffness on $3 \mathrm{~d}$ dynamic onbottom stability and importance for flexible flowlines, cables and umbilicals. ASME 2015 34th International Conference on Ocean, Offshore and Arctic Engineering, p.^pp. V05AT04A045-V05AT04A045.

Rosin, P. and Rammler, E., 1933. The laws governing the fineness of powdered coal. J. Inst. Fuel., 7: 29-36.

SAFEBUCK, 2015. Safe design of pipelines with lateral buckling: Safebuck iii design guideline, Atkins, Aberdeen.

Sharkey, F., 2013. Economic challenges and optimisation of ocean energy electrical systems.

Sharkey, F., Conlon, M. and Gaughan, K., 2013. Impacts on the electrical system economics from critical design factors of wave energy converters and arrays.

Sims, M., Smith, B. and Reed, T., 2004. Bayu-undan substructure foundations: Conception, design $\&$ installation aspects. Offshore Technology Conference, $p .^{\wedge}$ pp.

Stark, N., Hay, A.E. and Trowse, G., 2014. Cost-effective geotechnical and sedimentological early site assessment for ocean renewable energies. 2014 Oceans-St. John's, p.^pp. 1-8.

Stark, N., Hay, A.E., Trowse, G. and Kopf, A., 2013. Geotechnical investiogation of grand passage, nova scotia, with regard to sediment mobility and the installation of tidal energy converters. Proceedings of the European Wave and Tidal Energy Conference Series, p.^pp.

The Crown Estate, 2015. Emec pfow enabling actions project: Sub-sea cable lifecycle study.

White, D., Campbell, M., Boylan, N. and Bransby, M., 2012. A new framework for axial pipesoil interaction, illustrated by shear box tests on carbonate soils. Offshore Site Investigation and Geotechnics: Integrated Technologies-Present and Future, $\mathrm{p} .^{\wedge} \mathrm{pp}$.

Wilkinson, R., Palmer, A., Ellis, J., Seymour, E. and Sanderson, N., 1988. Stability of pipelines in trenches. Proceedings of the European Seminar on Offshore Oil and Gas Pipeline Technology, p.^pp.

Ziogos, A.D., Brown, M.J., Ivanovic, A. and Morgan, N., 2015. Rock-steel interface testing and considerations for gravity foundations for tidal energy generators. Frontiers in Offshore Geotechnics III. CRC Press. 
Figures 

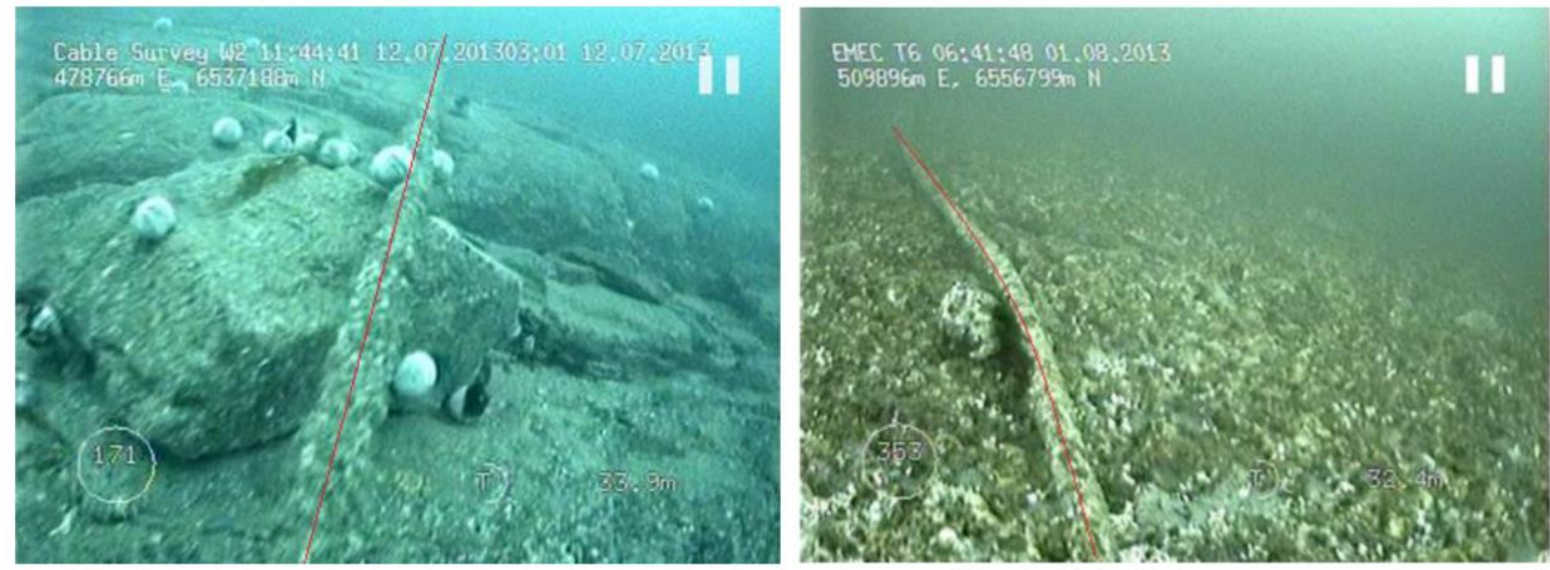

(1) at EMEC (Estate, 2015)
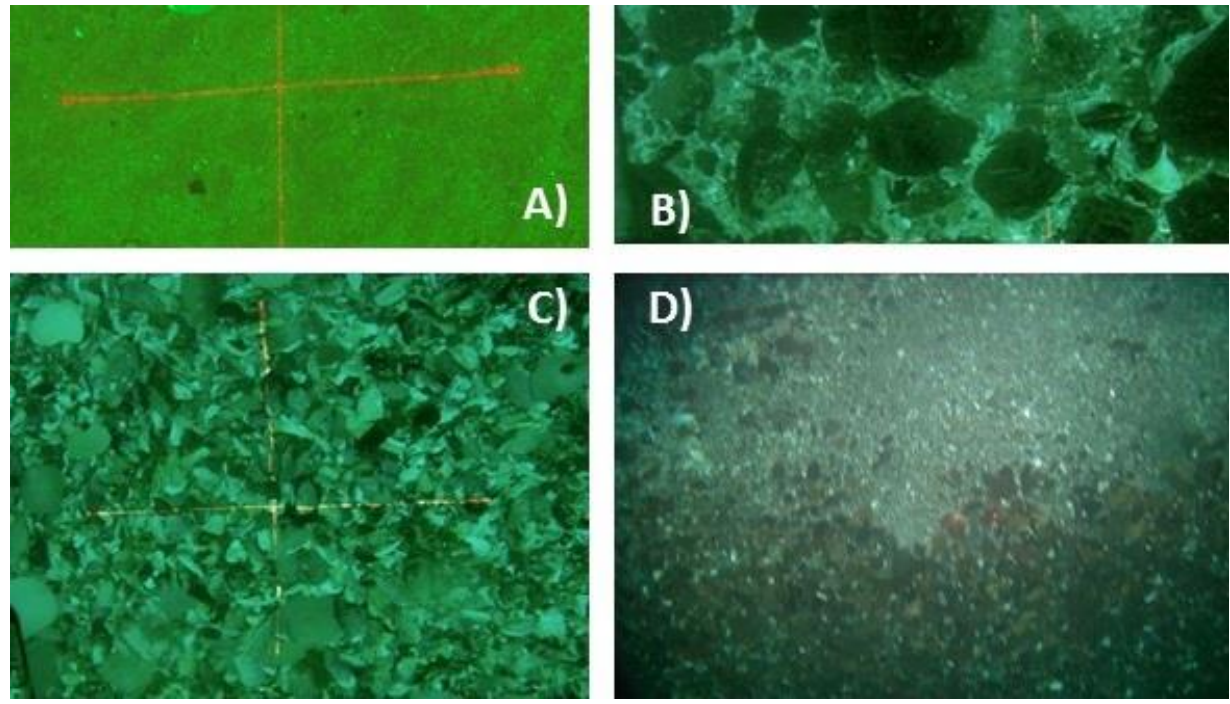

(2) Bay of Fundy (Stark et al., 2014)

Figure 1: Example rocky seabeds 


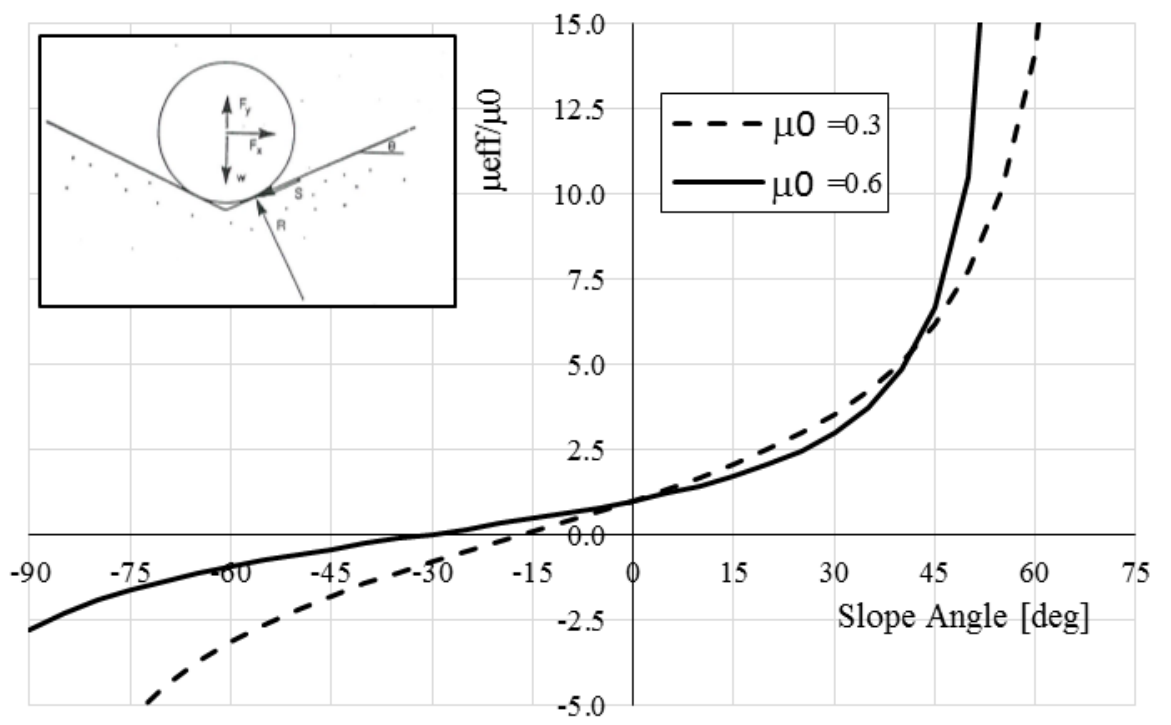

Figure 2: Pipe effective friction due to trench side-wall friction 
(a)

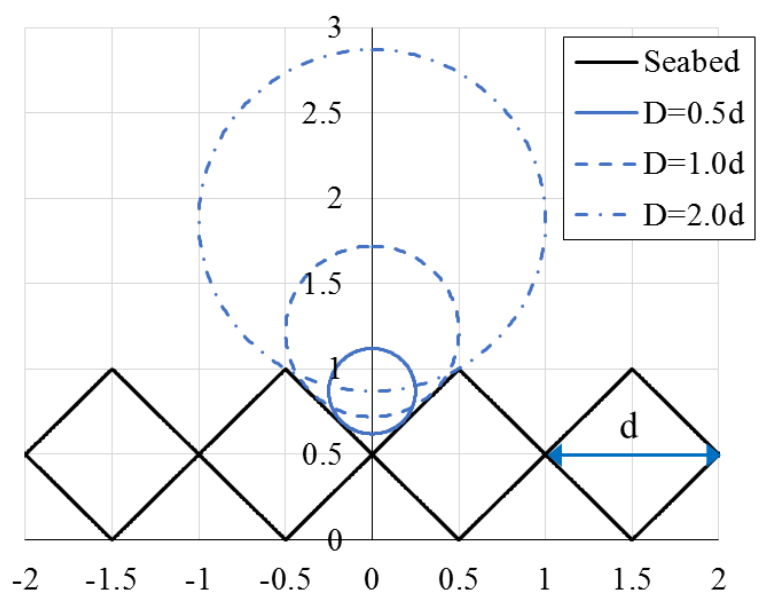

(c)

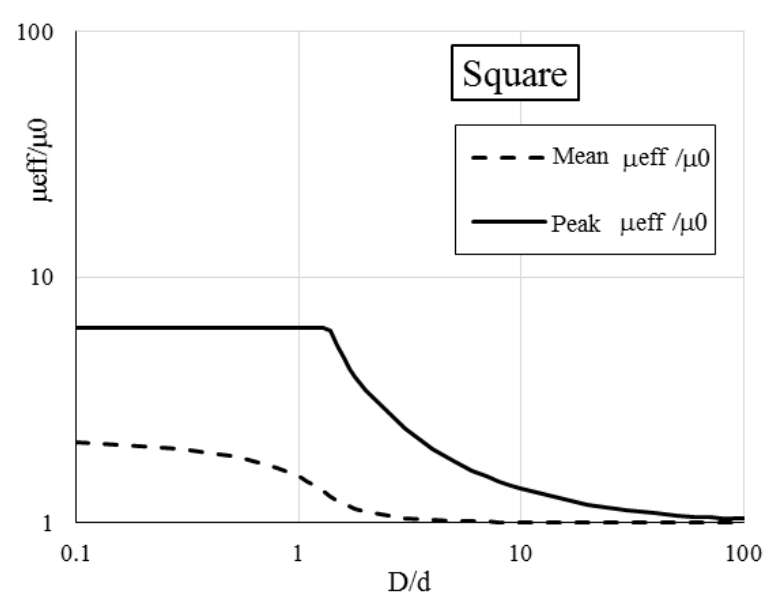

(b)

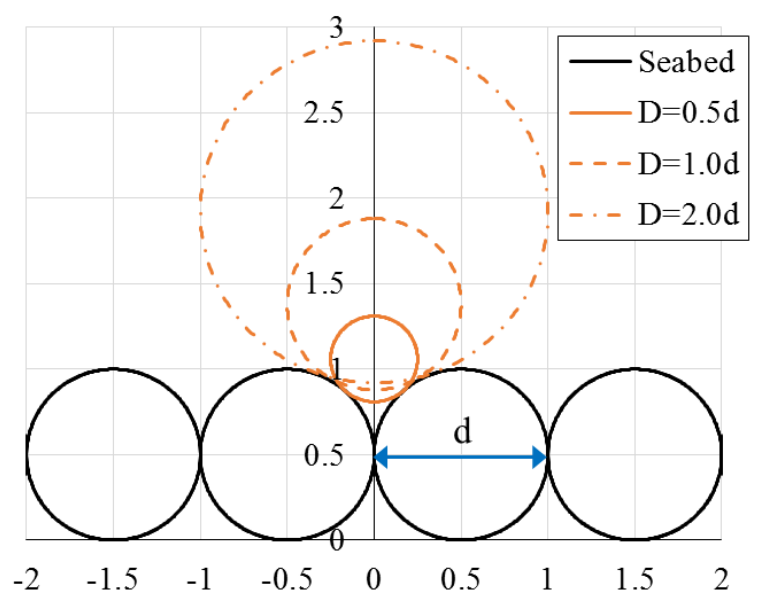

(d)

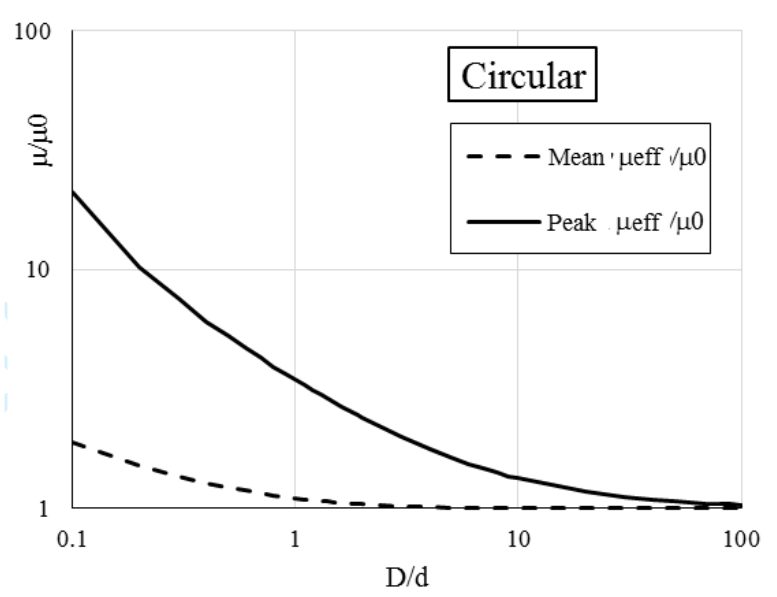

Figure 3: Pipe mean and peak lateral resistance on 2D regular seabed profiles $\left(\mu_{0}=0.3\right)$

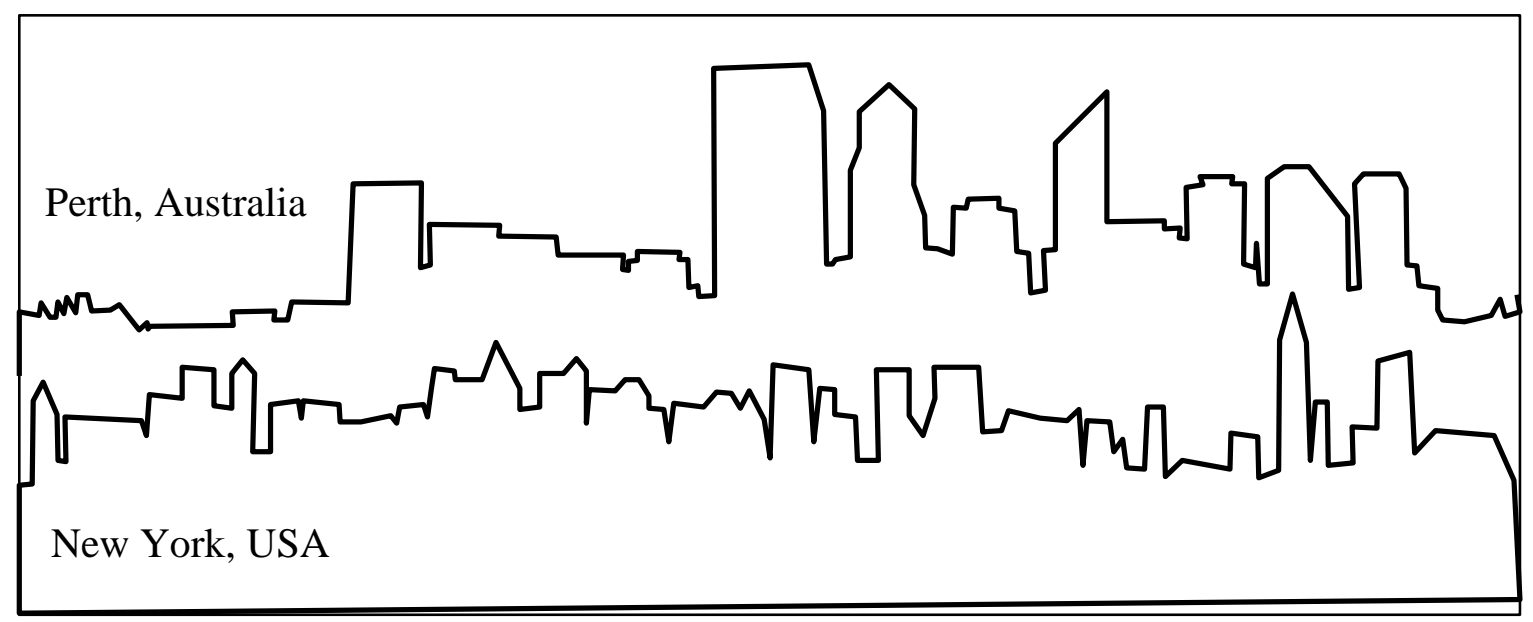

Figure 4: Example city skyline profiles 

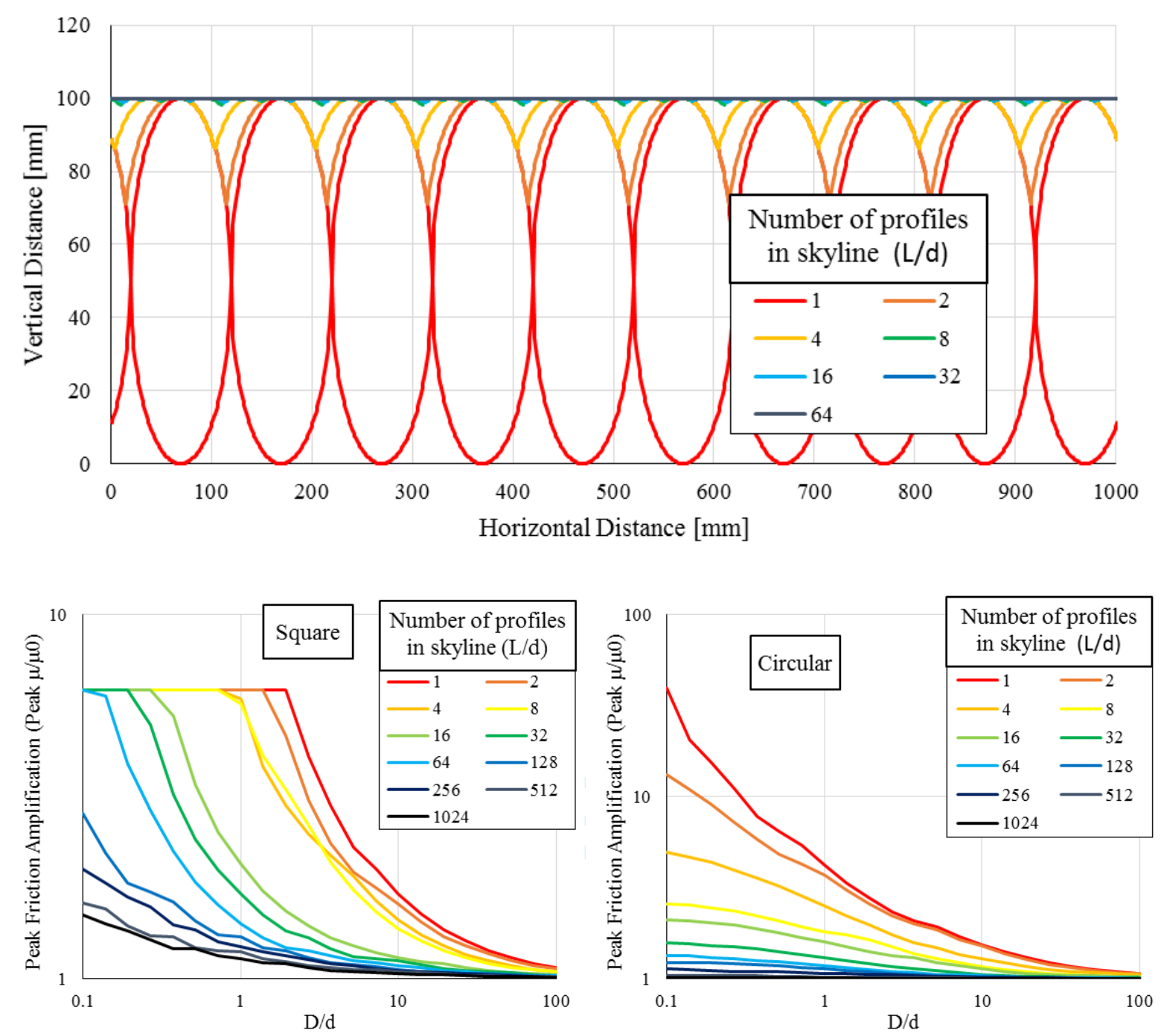

Figure 5: Variation of pipe profile gradient maxima versus D/d and number of regular square profiles in skyline 

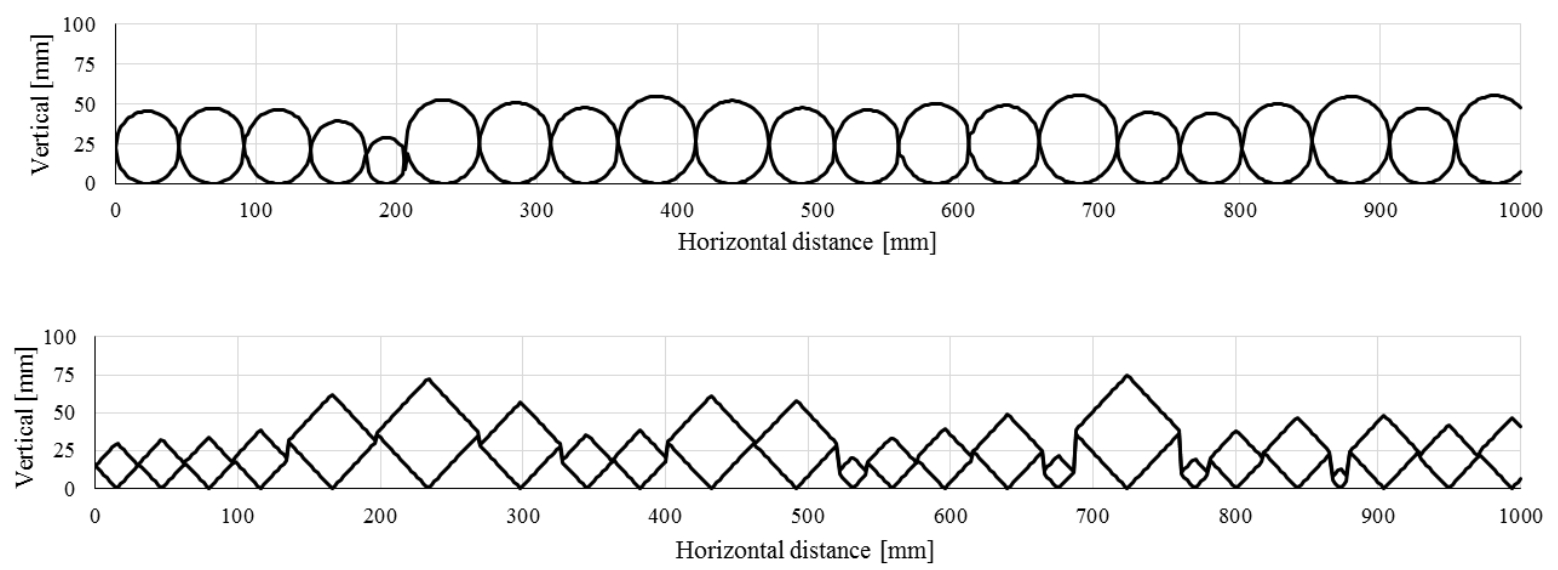

Figure 6: Irregular 2D profiles: $d_{n 50}=50 \mathrm{~mm}$; circular $C_{U}=1.3$; square $C_{U}=2.5$

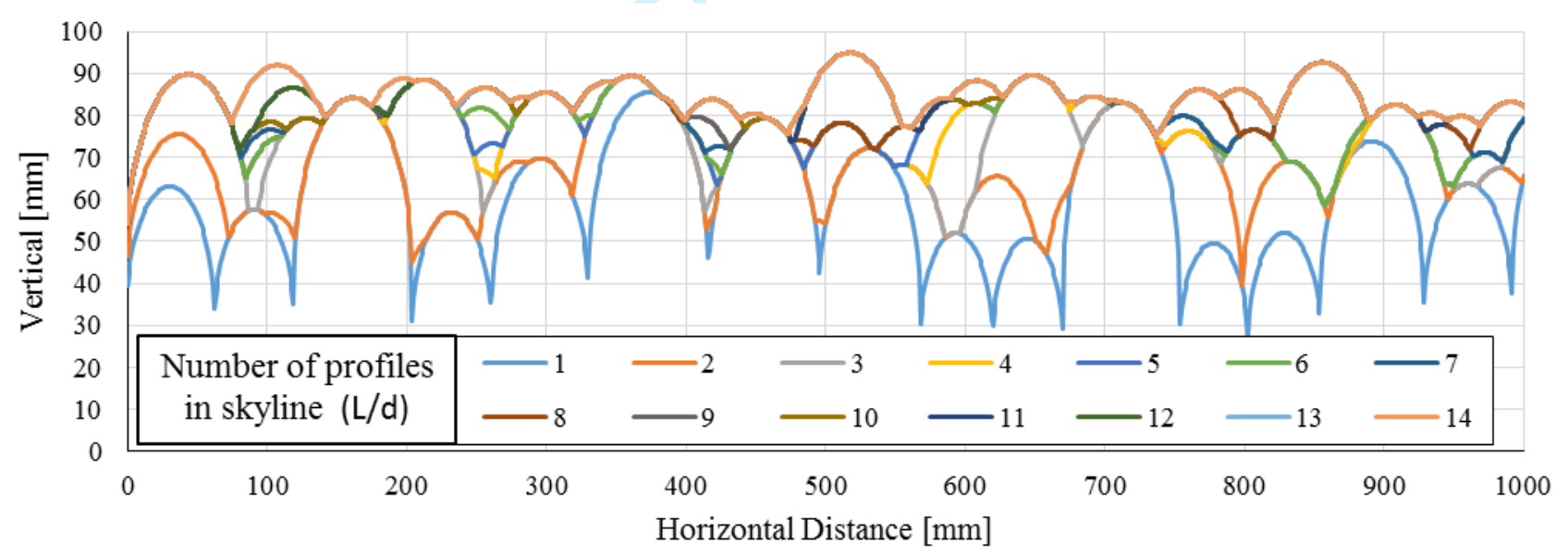

Figure 7: Cumulative skyline profile formed from irregular circular particle size distribution $\left(d_{n 50}=59.2 \mathrm{~mm}, \mathrm{C}_{\mathrm{U}}=\mathbf{1 . 3 6}\right)$ 

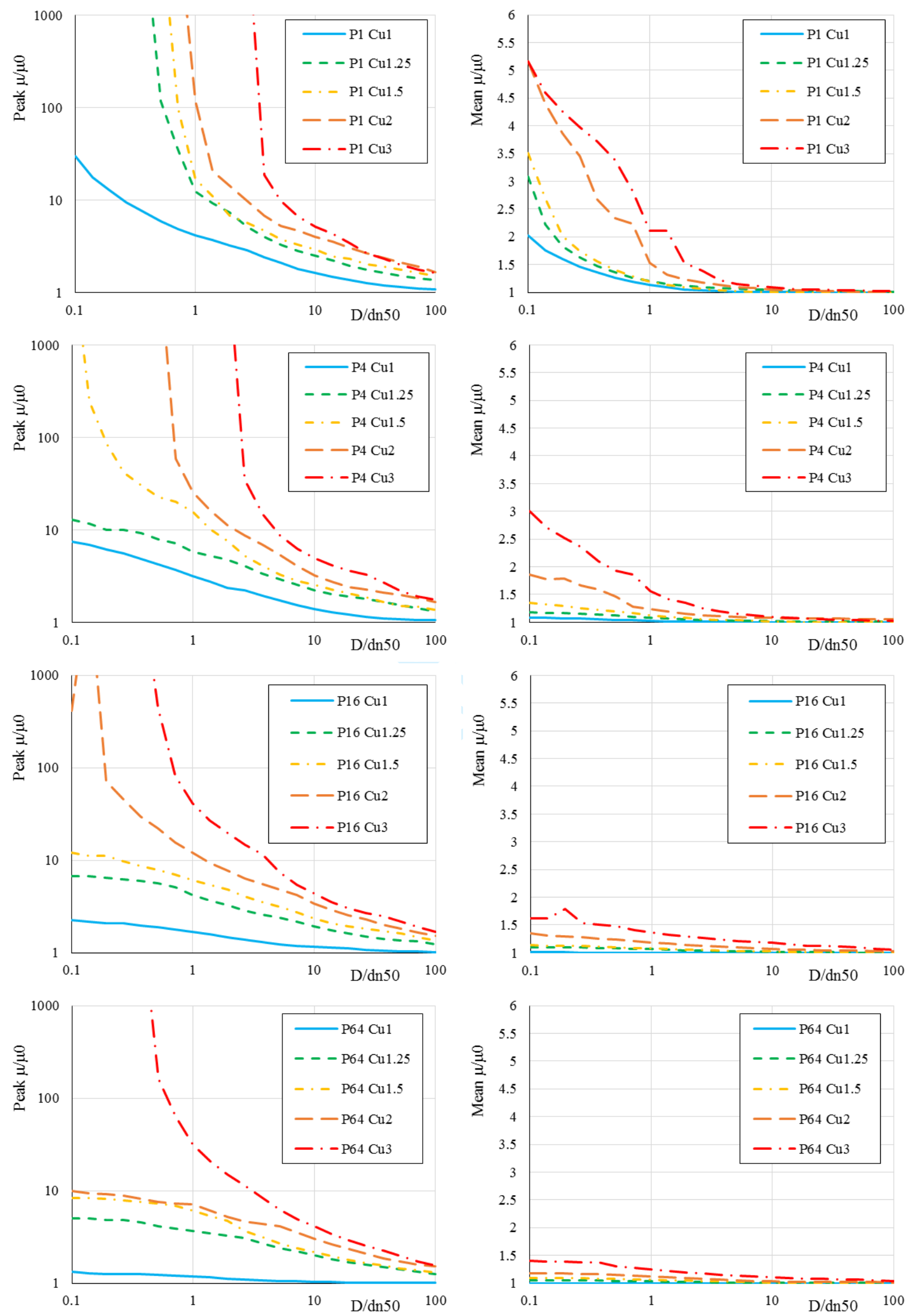

Figure 8: Comparison of pipe mean and maximum friction ratios from irregular quasi3D circular profiles with variation in number of profiles and $\mathrm{C}_{\mathrm{U}}$ 

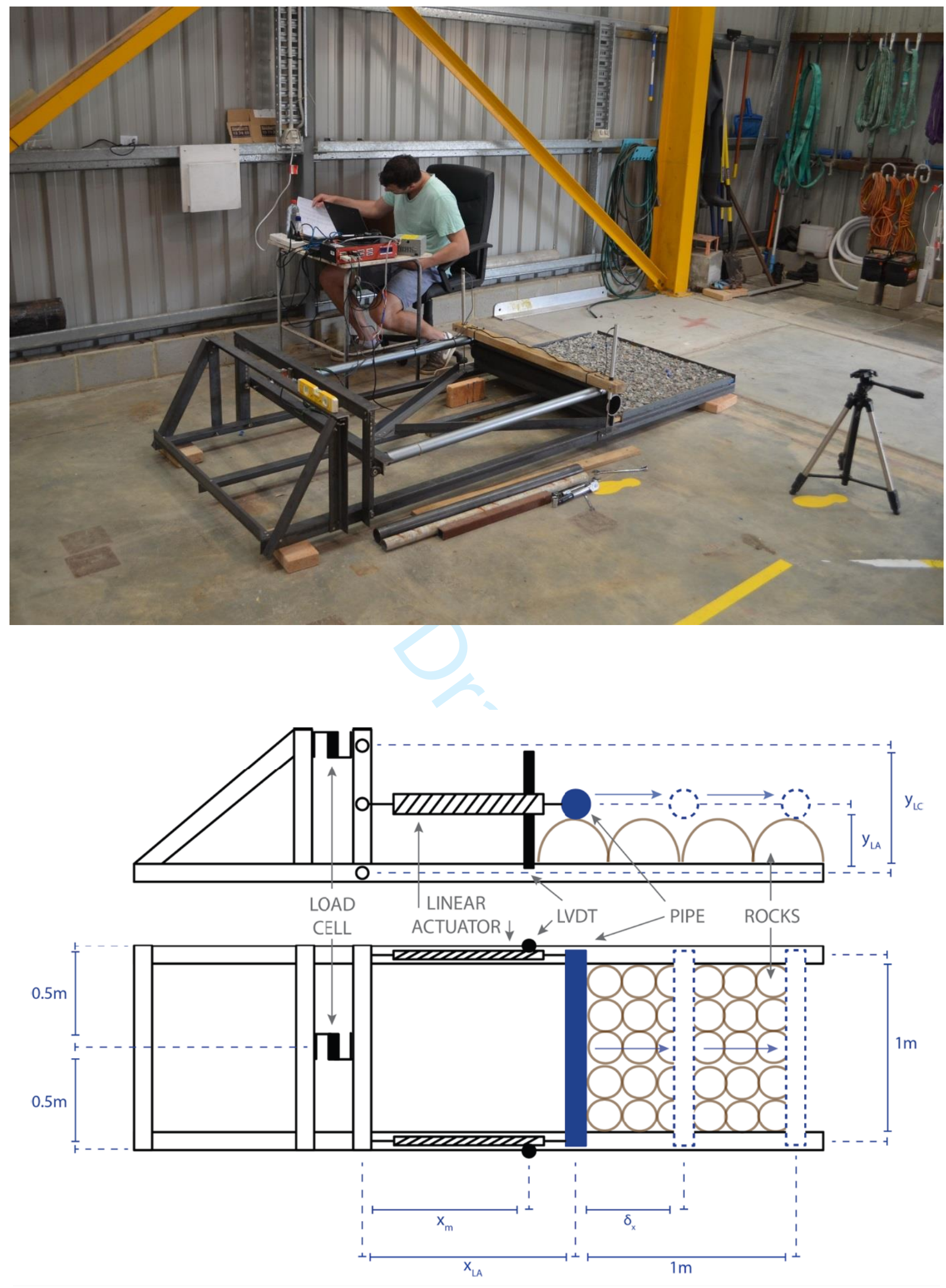

Figure 9: Photograph and schematic plan and elevation of lateral resistance test rig 


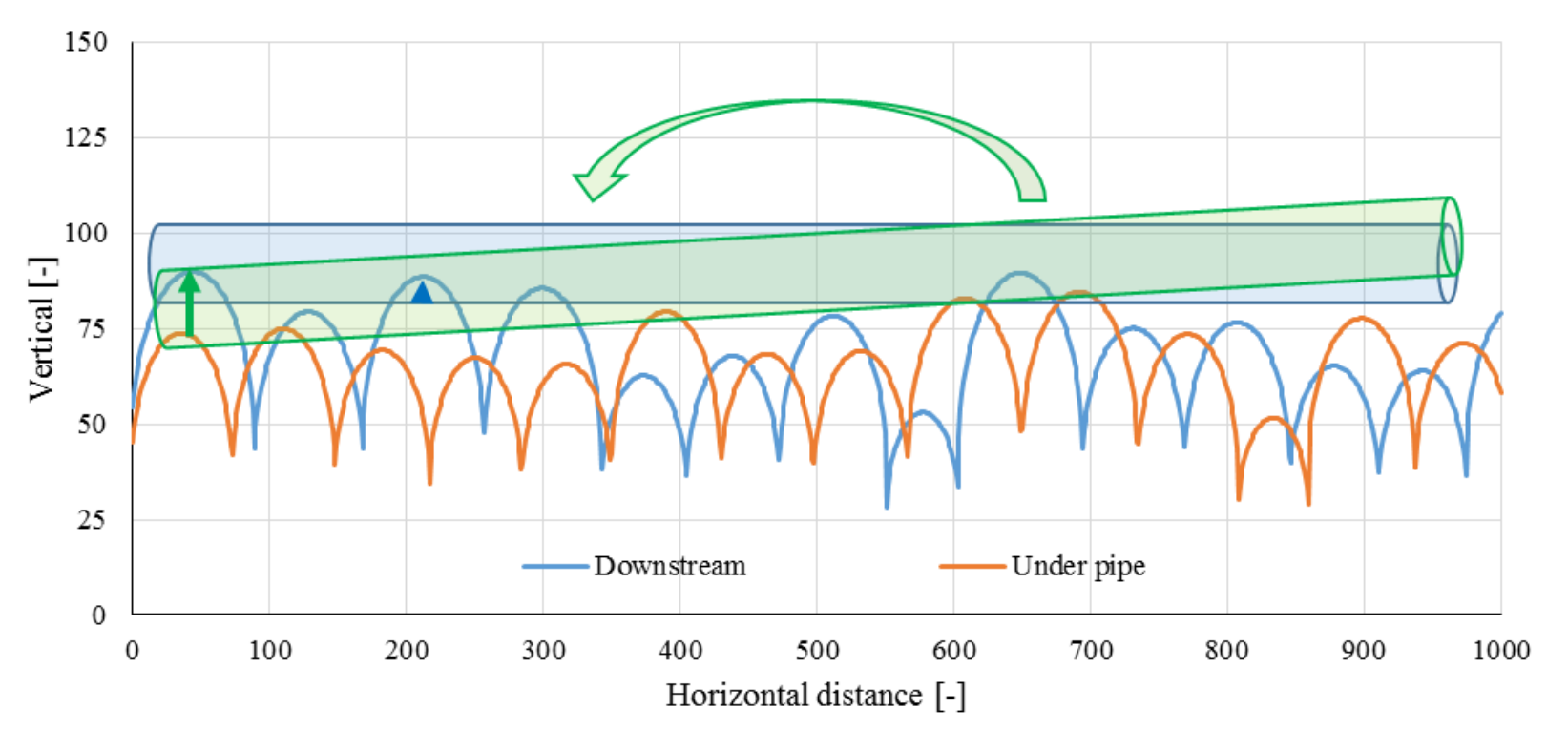

Figure 10: Effect of pipe yawing on lateral resistance over finite irregular profiles. Blue arrow shows step height for irrotational pipe compared to green arrow for pipe able to

$$
\text { 'yaw' }\left(d_{n 50}=59.2 \mathrm{~mm}, \mathrm{C}_{\mathrm{U}}=\mathbf{1 . 3 6}\right)
$$

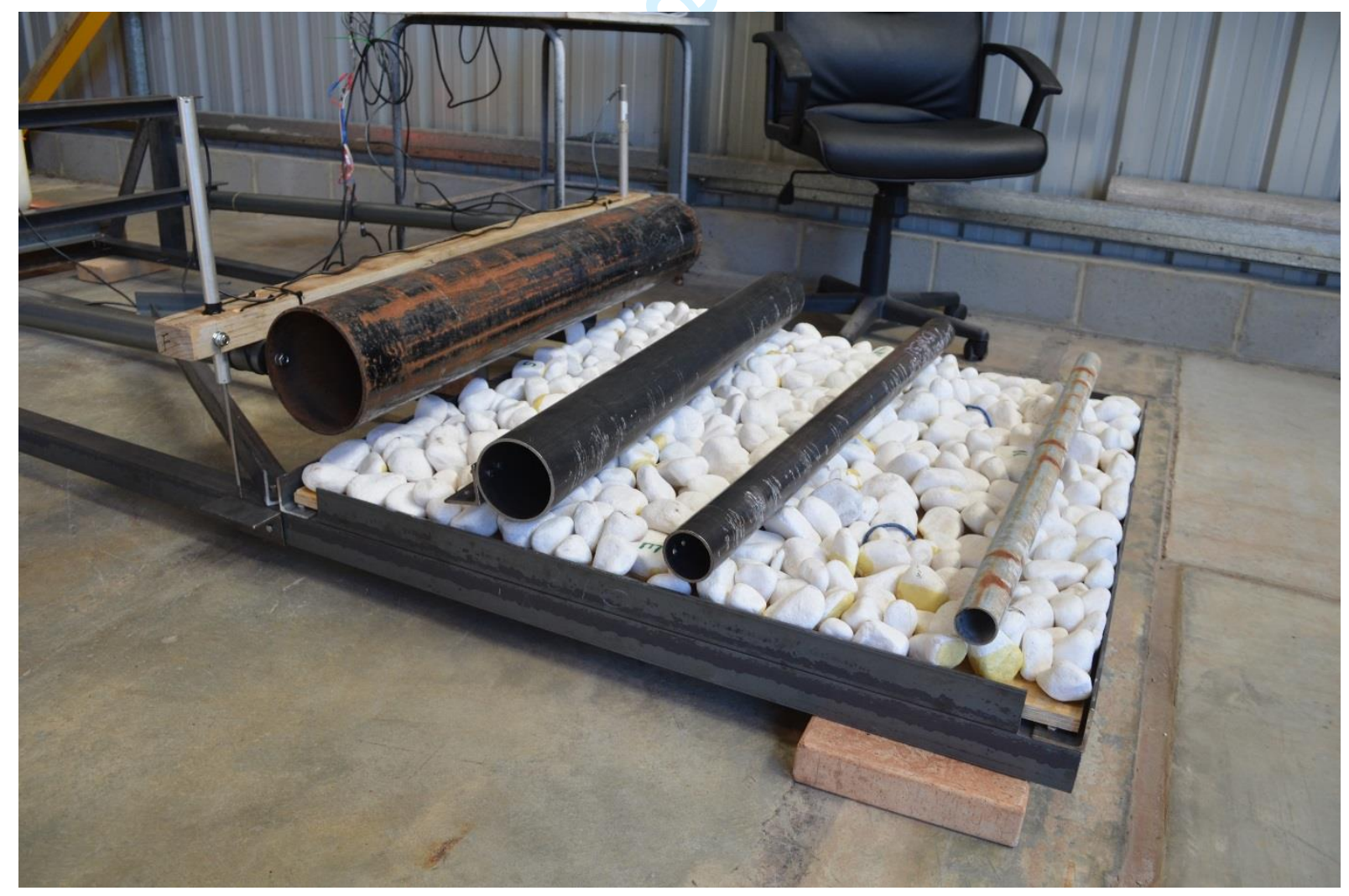

Figure 11: Four model pipes shown on round river stone test board 


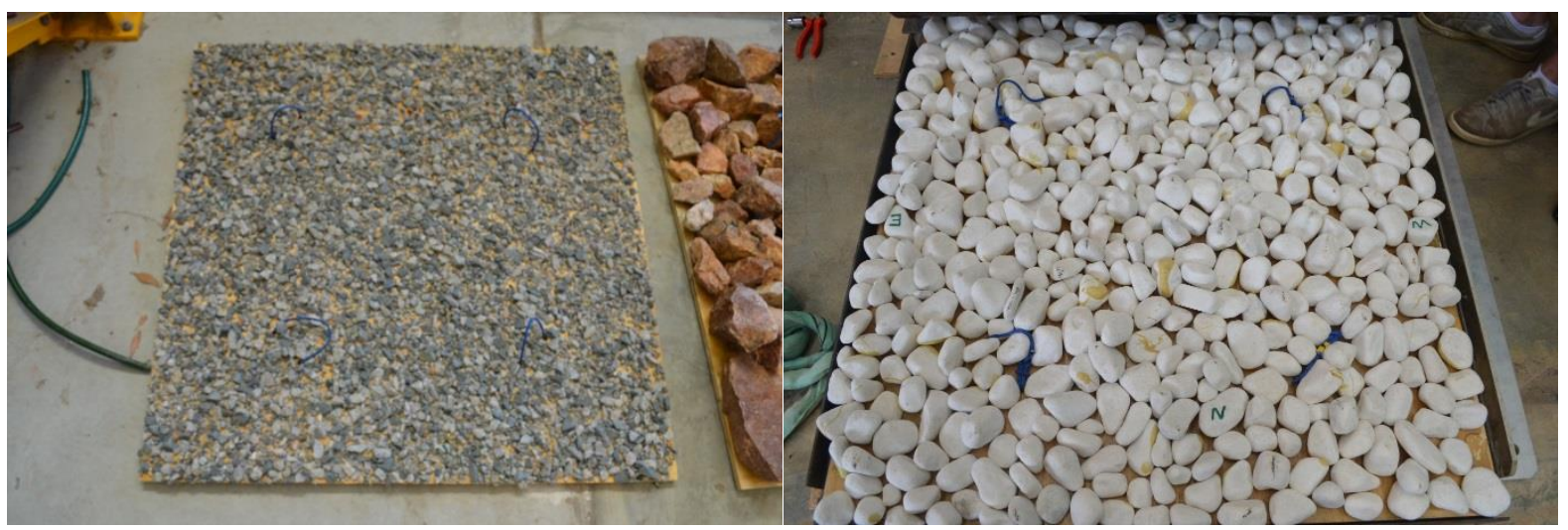

a) Blue Gravel stone test board

b) White Round stone test board

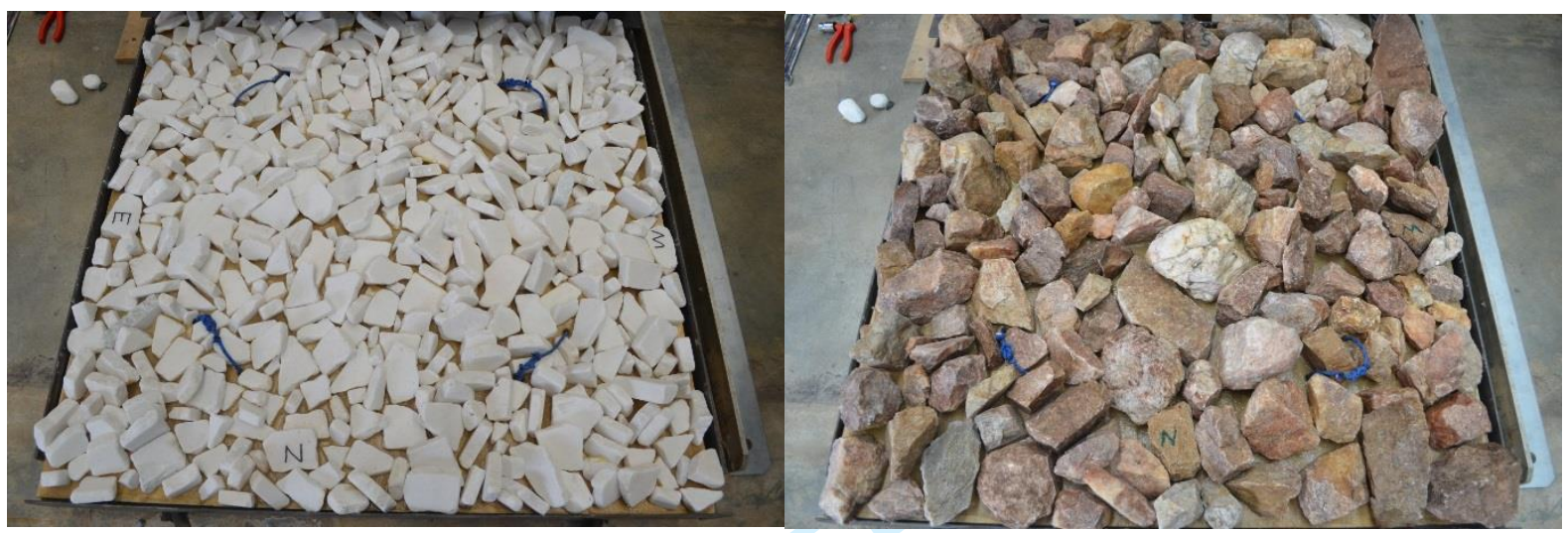

c) White Angular stone test board

d) Brown Angular stone test board

Figure 12: Stone test boards 


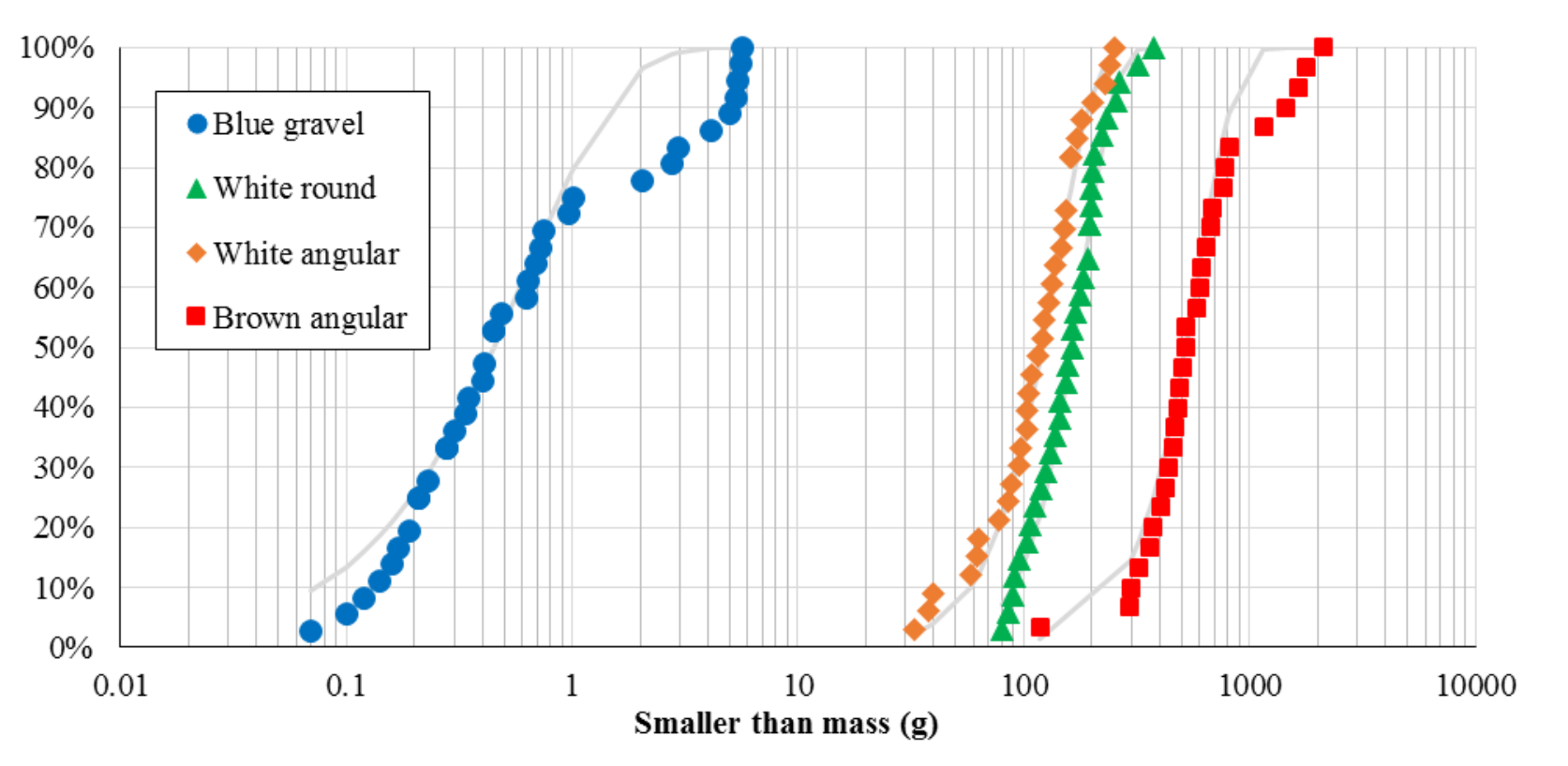

Figure 13: Rock sample grading curves (percentage passing by mass) 

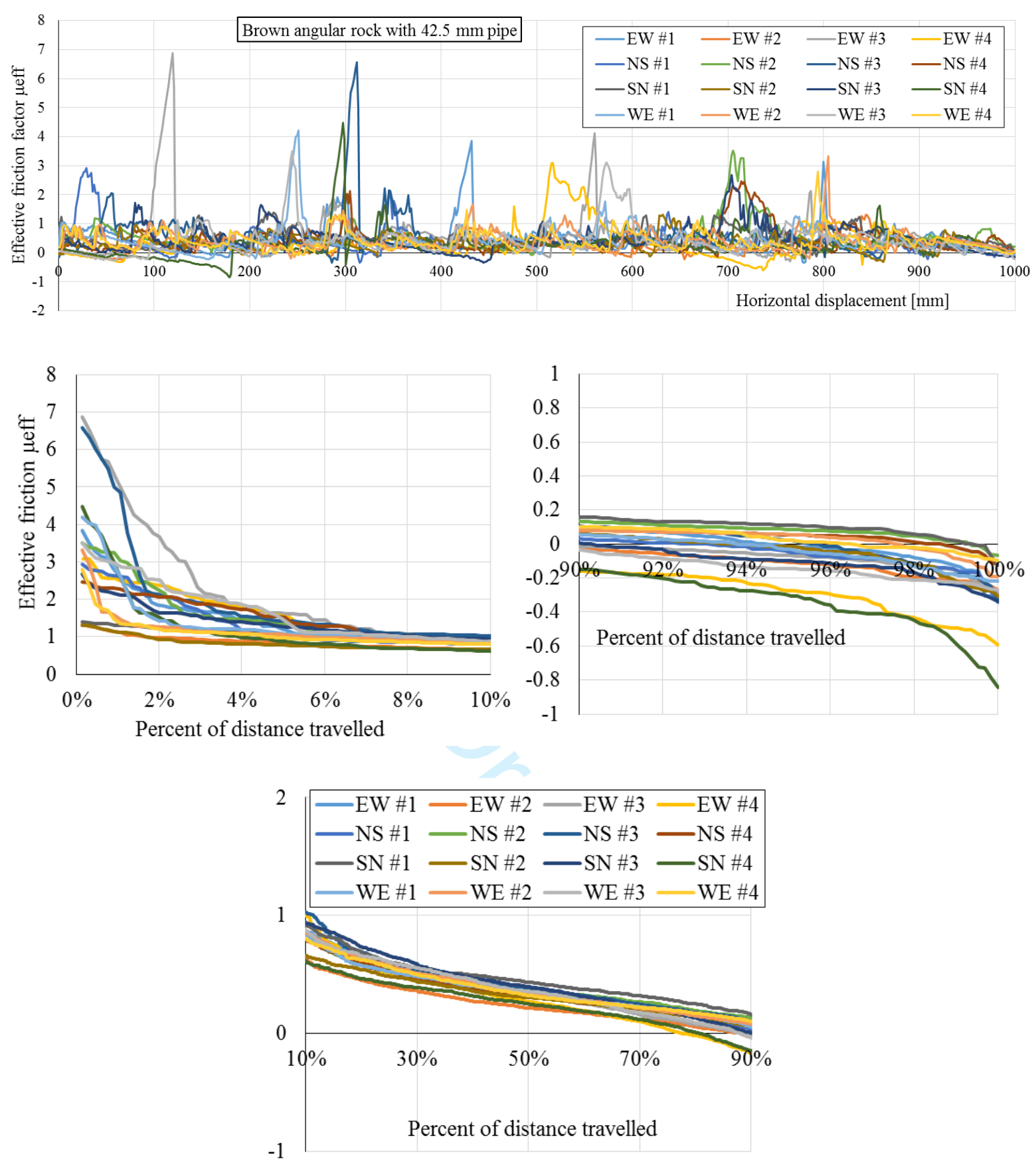

Figure 14: Effective friction factor vs displacement and sorted effective friction for Brown angular rock and $42.5 \mathrm{~mm}$ diameter pipe $\left(\mathrm{D} / \mathrm{d}_{\mathrm{n} 50}=0.72\right)$ 


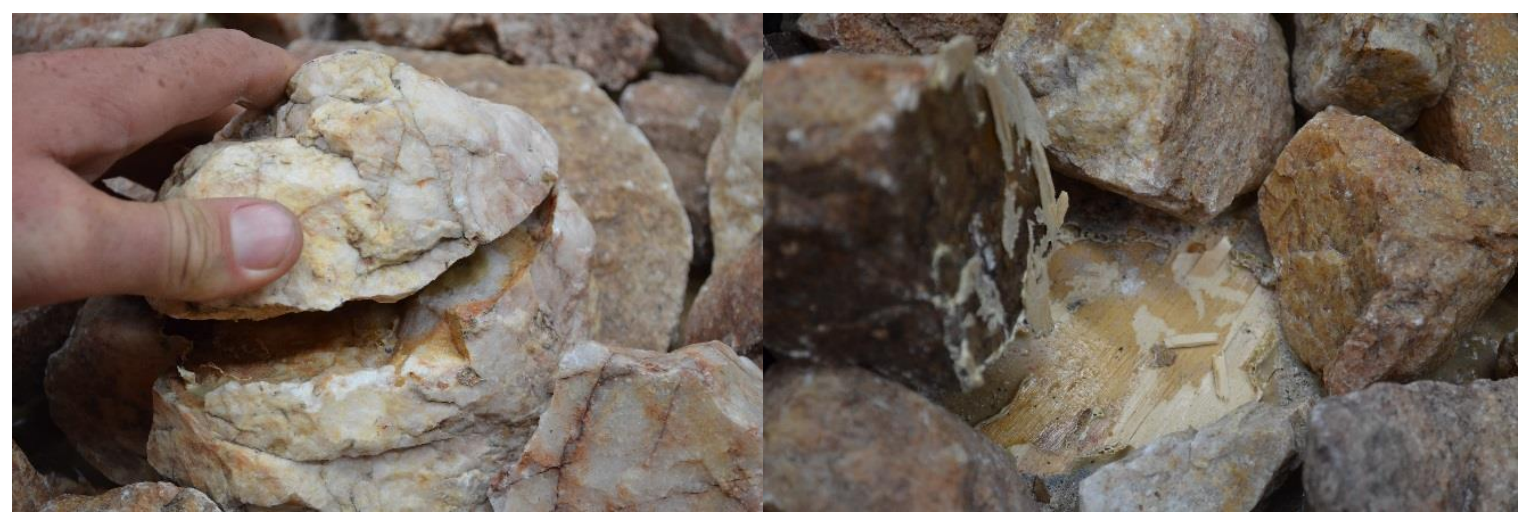

Figure 15: Testing issues - rock fracture (L) and rock/board adhesion failure (R) 


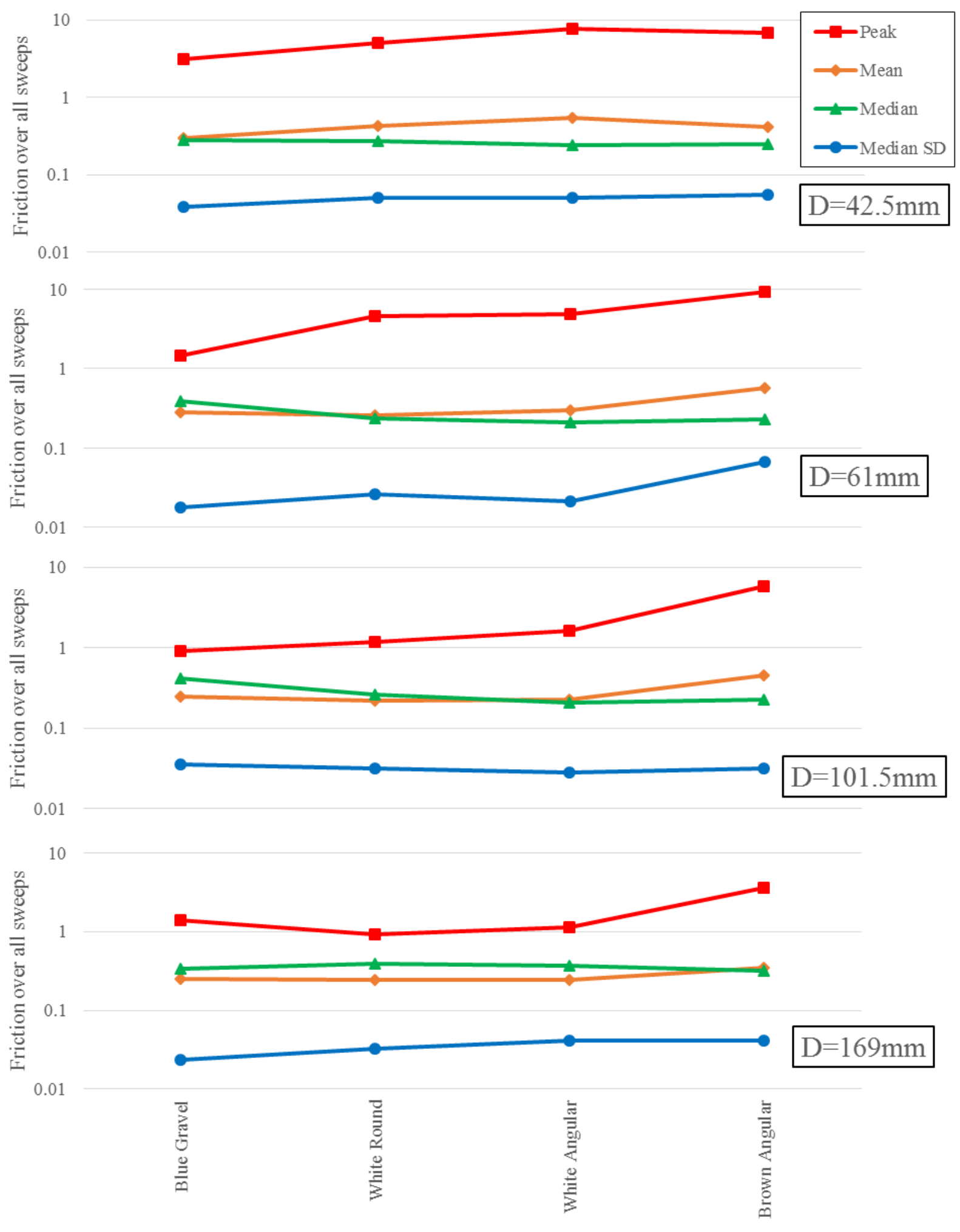

Figure 16: Physical test results summary 


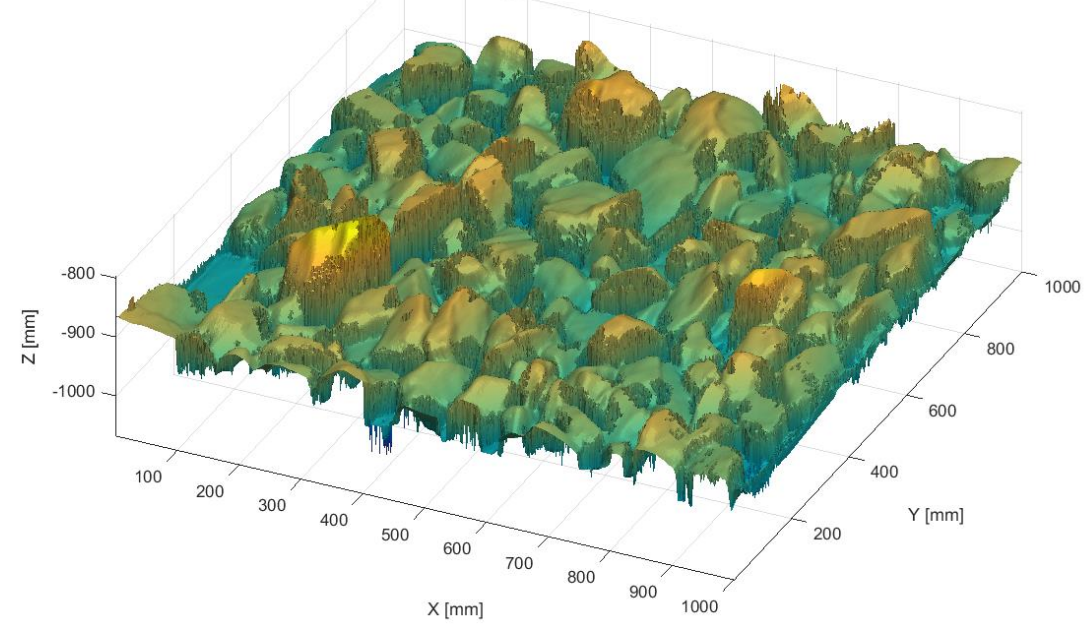

Figure 17: Scan of Brown Angular rock
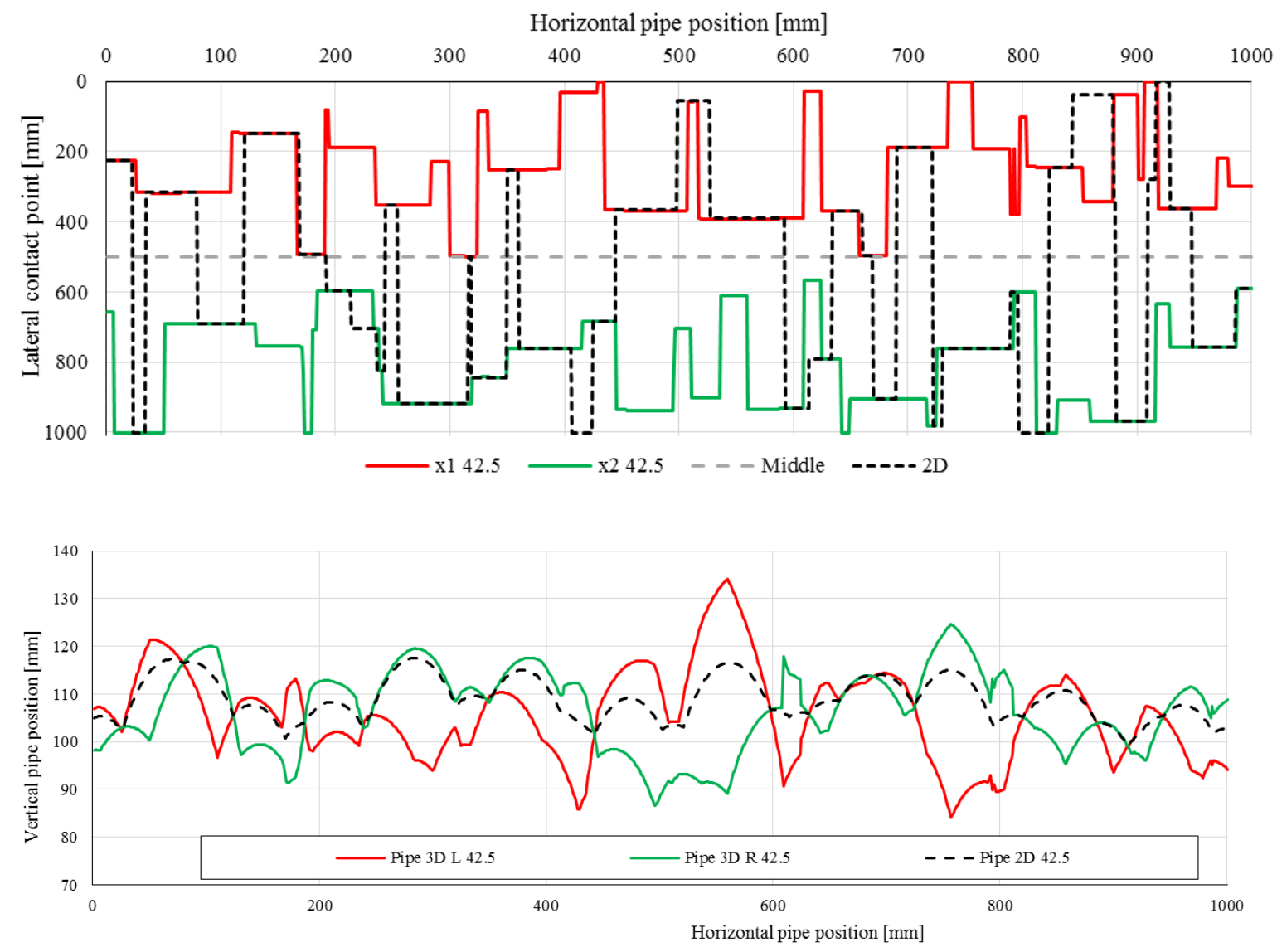

Figure 18: Lateral contact location and pipe end vertical elevation for $2 D$ versus 3D contact as a function of lateral pipe position (Brown angular rock scan 1) 

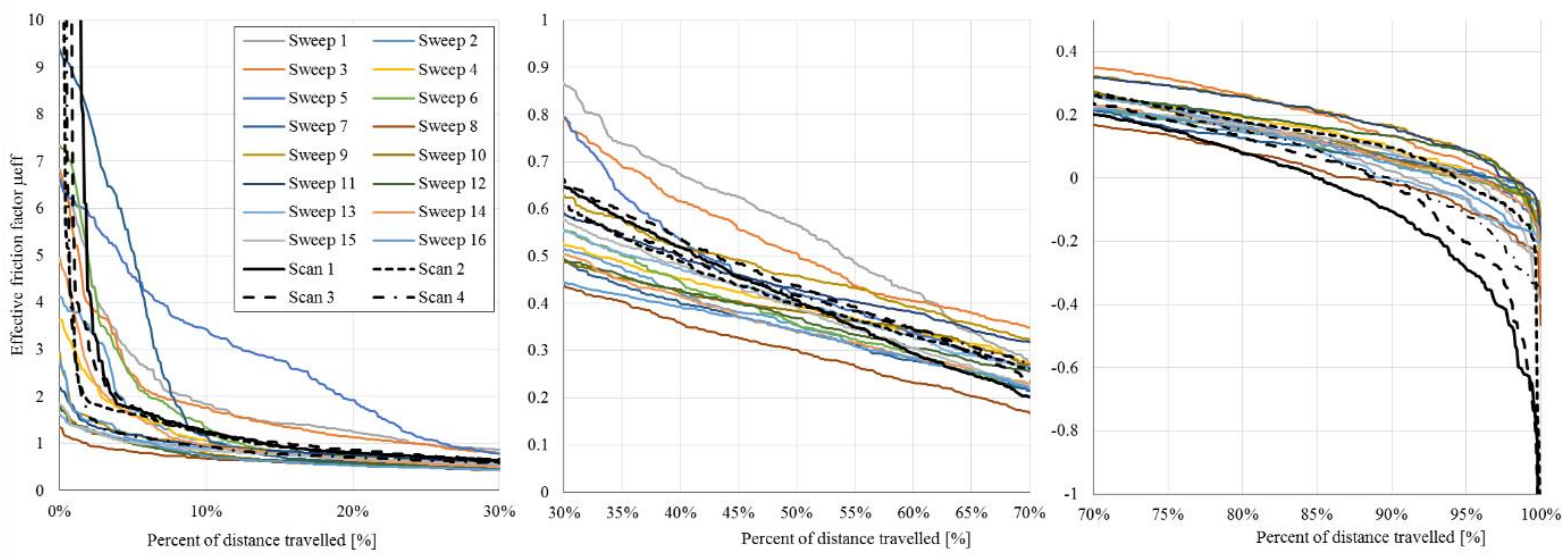

Figure 19: Comparison of effective friction distribution from scanned and measured tests (Brown angular rock, $61 \mathrm{~mm}$ pipe) 

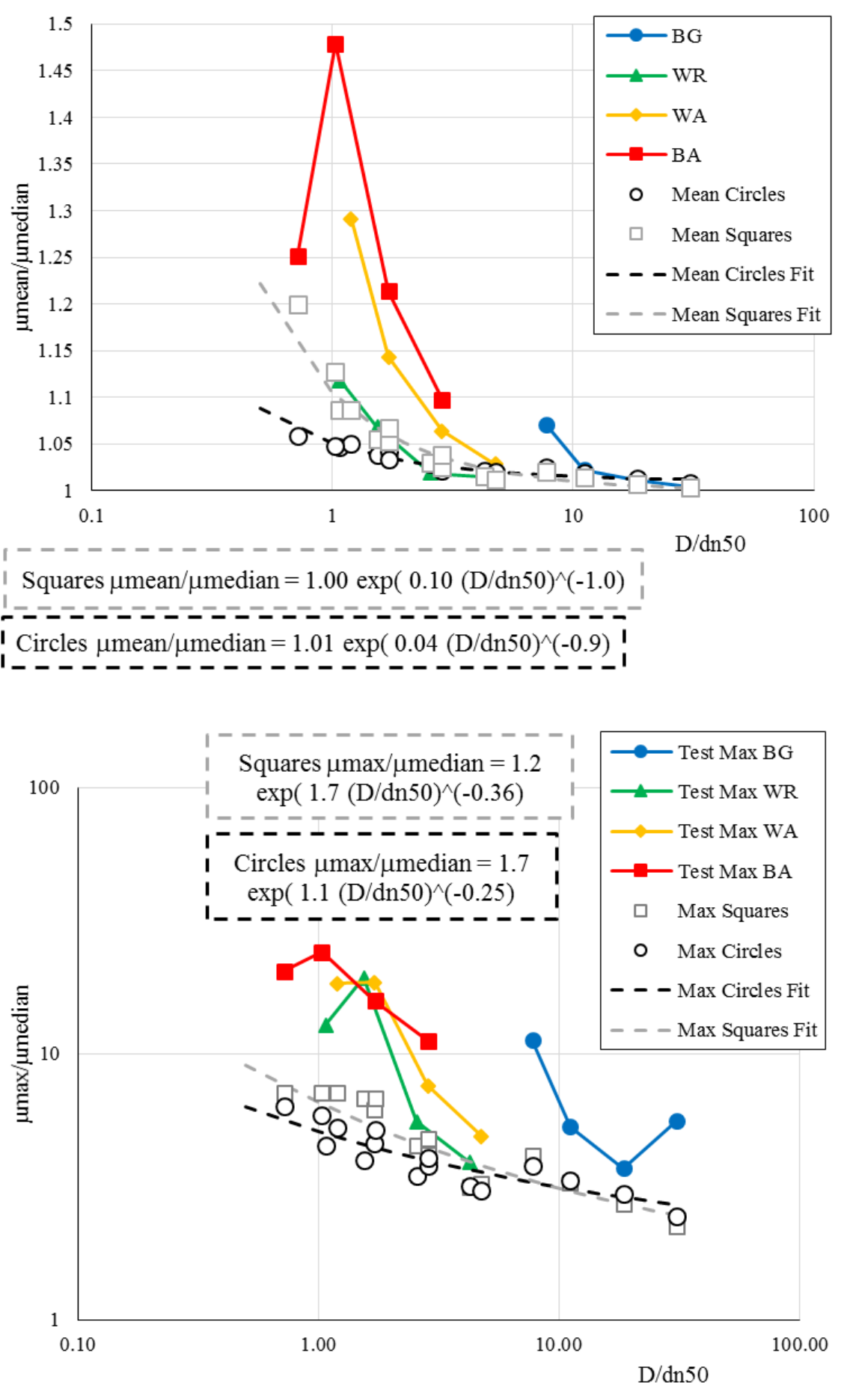

Figure 20: Comparison of maximum and mean friction amplification ratios for experimental and square / circular numerical results against D/dn50

Note: it is envisaged that these plots ought NOT to be used in design practice given as-yet they only capture SOME of the necessary physics describing pipe-rock-fluid interaction 

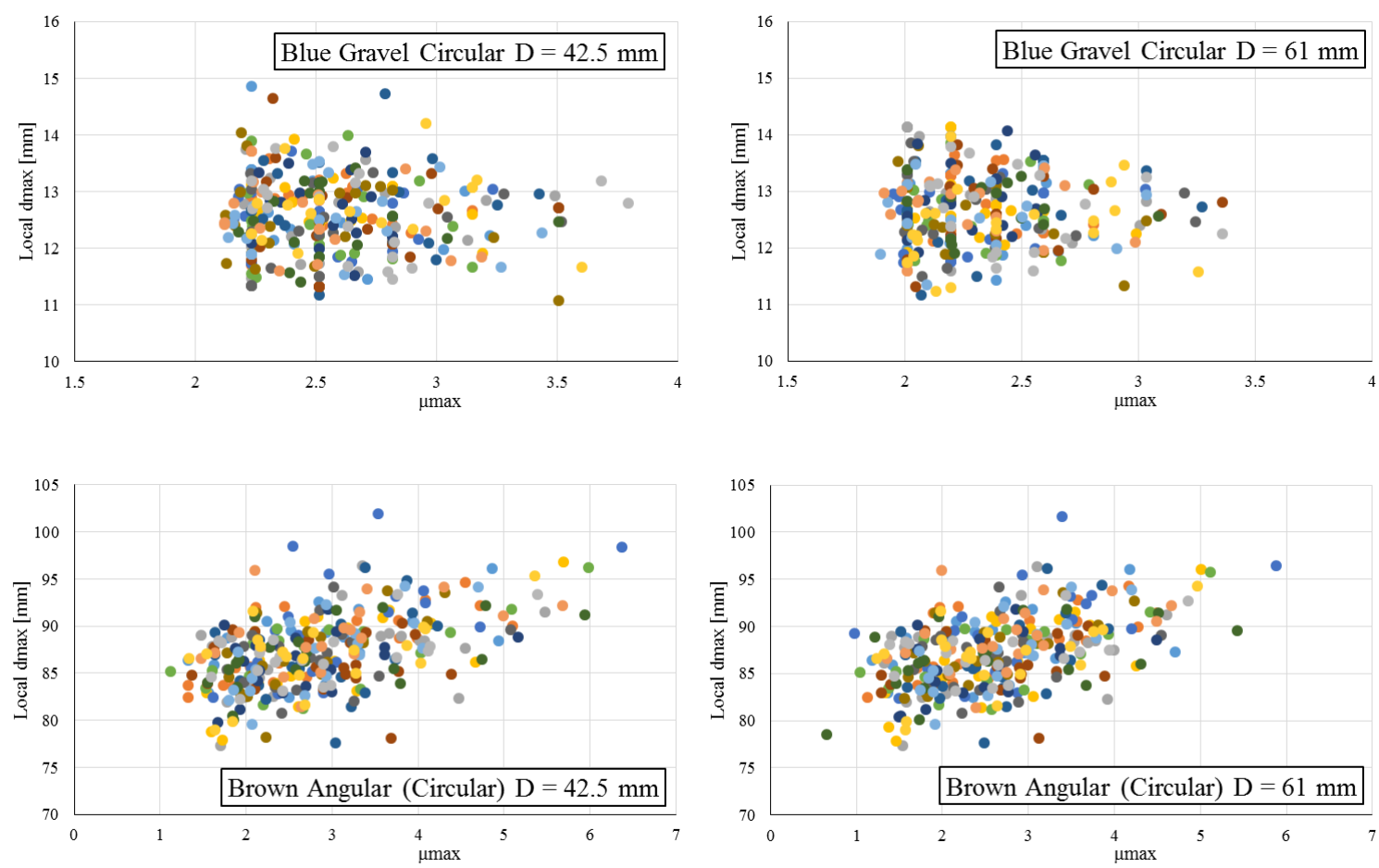

Figure 21: Comparison of synthetic simulations using spherical particles of peak friction versus adjacent maximum rock diameter

Note Blue gravel $\mathrm{d}_{\mathrm{n} 50}=5.5 \mathrm{~mm}, \mathrm{~d}_{\max }=18.1 \mathrm{~mm}$ overall

Brown angular $\mathrm{d}_{\mathrm{n} 50}=59.2 \mathrm{~mm}, \mathrm{~d}_{\max }=102.5 \mathrm{~mm}$ overall 

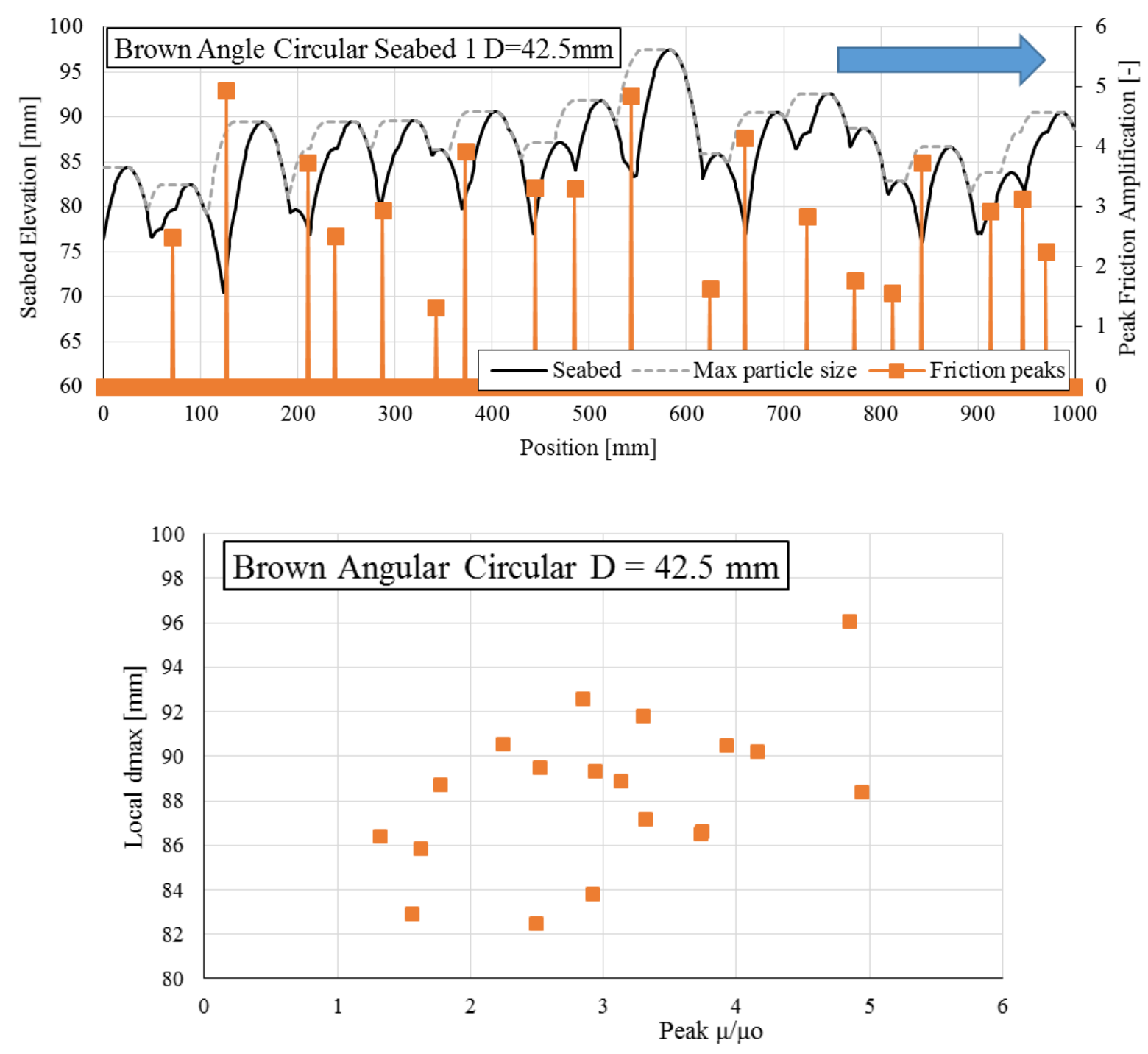

Figure 22: Correspondence between peak friction and particle size (Brown Angular rock simulation with circular particles $D=42.5 \mathrm{~mm}$ ) 